Check for updates

Cite this: RSC Adv., 2017, 7, 49633

Received 3rd October 2017

Accepted 13th October 2017

DOI: $10.1039 / c 7 r a 10920 b$

rsc.li/rsc-advances

\title{
Protein droplet actuation on superhydrophobic surfaces: a new approach toward anti-biofouling electrowetting systems $\dagger$
}

\author{
E. N. Abdul Latip, ${ }^{a}$ L. Coudron, (D) *a M. B. McDonnell, ${ }^{\text {ab }}$ I. D. Johnston, ${ }^{a}$ \\ D. K. McCluskey, ${ }^{a}$ R. Day ${ }^{a}$ and M. C. Tracey ${ }^{a}$
}

Among Lab-on-a-chip techniques, digital microfluidics (DMF), allowing the precise actuation of discrete droplets, is a highly promising, flexible, biochemical assay platform for biomedical and bio-detection applications. However the durability of DMF systems remains a challenge due to biofouling of the droplet-actuating surface when high concentrations of biomolecules are employed. To address this issue, the use of superhydrophobic materials as the actuating surface in DMF devices is examined. The change in contact angle by electrowetting of deionised water and ovalbumin protein samples is characterised on different surfaces (hydrophobic and superhydrophobic). Ovalbumin droplets at $1 \mathrm{mg} \mathrm{m}{ }^{-1}$ concentration display better electrowetting reversibility on Neverwet ${ }^{\circledR}$, a commercial superhydrophobic material, than on Cytop ${ }^{\circledR}$, a typical DMF hydrophobic material. Biofouling rate, characterised by roll-off angle measurement of ovalbumin loaded droplets and further confirmed by measurements of the mean fluorescence intensity of labelled fibrinogen, appears greatly reduced on Neverwet ${ }^{\circledR}$. Transportation of protein laden droplets (fibrinogen at concentration $0.1 \mathrm{mg} \mathrm{ml}^{-1}$ and ovalbumin at concentration $1 \mathrm{mg} \mathrm{ml}^{-1}$ and $10 \mathrm{mg} \mathrm{ml}^{-1}$ ) is successfully demonstrated using electrowetting actuation on both single-plate and parallel-plate configurations with performance comparable to that of $\mathrm{DI}$ water actuation. In addition, although droplet splitting requires further attention, merging and efficient mixing are demonstrated.

$$
\cos \theta=\cos \theta_{\mathrm{c}}+\frac{\varepsilon_{\mathrm{o}} \varepsilon_{\mathrm{r}}}{2 \gamma_{\mathrm{lg}} d} V^{2}=\cos \theta_{\mathrm{c}}+\eta
$$

\section{Introduction}

The application of 'Lab on a Chip' techniques to modern bioassay technologies such as Enzyme Linked Immunosorbent Assay (ELISA) ${ }^{1-6}$ and Polymerase Chain Reaction (PCR) ${ }^{6-9}$ has been the subject of extensive research. ${ }^{\mathbf{1 0 - 1 2}}$ Digital microfluidics (DMF) has emerged as a promising technique for such assays due to small sample volume, typically at microliter scale, resulting in fast reaction times and minimal use of reagents and samples, offering non-dispersive reagent transport (compared to continuum microfluidics) facilitating all bioassay protocols and, finally, allowing high automation capacity for implementing complex protocols. DMF achieves precise spatial control of droplets using the principle of electrowetting-ondielectric (EWOD) by which the apparent contact angle (CA) $\theta$ of a droplet sitting on a dielectric layer is modified by regulation of the voltage $\mathrm{V}$ applied between the droplet and the surface as described by the Young-Lippmann equation (eqn (1)): ${ }^{13-15}$

\footnotetext{
${ }^{a}$ School of Engineering and Technology, University of Hertfordshire, College Lane, Hatfield, AL10 9AB, UK. E-mail: l.coudron@herts.ac.uk

${ }^{b}$ Dstl Porton Down, Salisbury, Wiltshire, SP4 OJQ, UK

$\dagger$ Electronic supplementary information (ESI) available: Videos of protein droplet actuation. See DOI: 10.1039/c7ra10920b
}

where $\theta_{\mathrm{c}}$ is the CA without voltage application (i.e. the Young angle), $\varepsilon_{\mathrm{o}}$ is the permittivity of free space, $\varepsilon_{\mathrm{r}}$ is the dielectric constant, $\gamma_{\mathrm{lg}}$ is the liquid-gas surface tension and $d$ is the dielectric layer thickness. The dimensionless electrowetting number $\eta$ represents the ratio between the electrostatic energy and the free energy at the liquid|gas interface. Fully automated DMF devices have been successfully demonstrated by several groups $^{\mathbf{1 - 4 , 6 - 8 , 1 3 , 1 6 - 2 2}}$ exploiting EWOD's capability to individually control droplet samples via specific control electrode activation sequences.

There are two common configurations of EWOD-based DMF devices: the single-plate (or 'open') and the parallel-plate (or 'closed') configuration. Most reported devices ${ }^{\mathbf{1 - 4 , 6 - 8 , 1 3 , 1 6 - 2 2}}$ use the parallel-plate configuration, both because it provides reliable droplet volumes by protecting droplets from evaporation and because droplets in parallel-plate devices are less affected by gravity than single-plate devices. In a parallel-plate device, two plates sandwich the actuation medium which can be either air or an immiscible fluid such as silicone oil. ${ }^{13,21,23}$ The base plate comprises the array of control electrodes below the hydrophobic and dielectric layers while the cover plate constitutes the ground electrode. There are also reports of parallel-plate with 
passive cover plate ${ }^{24-26}$ but this configuration requires a specific design of the base plate's control electrodes. Although earlier work indicates that such passive setup would be unworkable with a typical square electrode design, ${ }^{21}$ the present study suggests that using superhydrophobic material would permit the very simple square electrode design ${ }^{\mathbf{1 - 4 , 6 - 8 , 1 3 , 1 7 - 2 2}}$ to be used in a functional passive cover plate configuration, thus, reducing complexity in both fabrication and electrical integration of the electrowetting actuator and allowing accommodation of other bioassay functions while still maintaining the droplet control advantages of two plates rather than a single plate..$^{25}$

Despite its many advantages, the full potential of DMF for bioassay applications will not be achieved without successfully addressing the question of device reliability when 'real life' samples are used. 'Real life' samples, because they typically contain high concentrations of biomolecules, can cause contamination of the actuation surface, generally referred to as biofouling, by deposition of solid inclusions (e.g. microorganisms) or by the adsorption of biomolecules (e.g. proteins). ${ }^{4}$ The subsequent motion of droplets is impeded at the contaminated location thus compromising the device's reliability and limiting its lifetime. Whilst the biofouling rate can be mitigated by preDMF 'sample prep' processes, this reduces the operational and commercial advantages of DMF bioassays.

A silicone oil medium has been used in some studies ${ }^{17,21,23}$ to reduce biofouling but this approach requires specific device packaging to avoid leakage ${ }^{4}$ and is challenging in terms of transportability and connectivity with other microfluidic devices. There is also the risk of oil components infiltrating the droplet thus interfering with the droplet's chemistry. ${ }^{27}$ Another approach to reducing biomolecular adsorption is by adding a pluronic surfactant to the droplet. ${ }^{28}$ This method has its drawbacks as the use of surfactant could reduce the electrowetting performance by altering the droplet viscosity and surface tension. In the same way as an oil medium, the surfactant could also change the droplet's chemistry thus affecting the outcome of the bioassay. ${ }^{29}$

Teflon ${ }^{\mathrm{TM}} \mathrm{AF}^{\mathbf{1 , 3 , 4 , 1 3 , 1 6 - 1 8 , 2 1}}$ and Cytop ${ }^{{ }^{30,31}}$ have been the prevailing materials used for the realisation of hydrophobic surfaces in DMF because they provide high static contact angles $\left(\sim 110^{\circ}\right)$. They also display high electrowetting reversibility (the ability of droplet CA to return to its initial value after voltage application) with low hysteresis for most types of solutions. However, these materials are prone to biofouling and therefore have low durability when solutions with a high concentration of biomolecules are used. ${ }^{32}$ They are also quite expensive proprietary technologies. Accordingly, some studies have evaluated low cost, commercial, off-the-shelf 'rain repellent' hydrophobic materials such as Rain-X, ${ }^{33}$ Nevosil Si-7100, ${ }^{34}$ and Avam..$^{34}$ These products have demonstrated promising performance as actuating surfaces but their robustness with 'real life' samples has yet to be investigated.

Beyond hydrophobicity, a surface is characterised as superhydrophobic when its static CA is larger than $150^{\circ}$. This property is produced by combining micro and nanostructures with low surface energy. A key component in the development of superhydrophobic surfaces is the introduction of surface roughness by the micro and nanostructures which feature is also present in naturally occurring superhydrophobic surfaces (e.g. butterfly wings, colocasia leaves and lotus leaves). ${ }^{35-37}$ Wang \& Jiang $^{37}$ described five possible states of superhydrophobic surfaces: Wenzel state, Cassie-Baxter state, Lotus state (special case of Cassie-Baxter state), transitional state between Wenzel and Cassie-Baxter states, and 'Gecko' state. In both CassieBaxter state and Lotus state, the superhydrophobic surfaces gain a self-cleaning property due to the high CA which reduces liquid droplet contact area with the surface and provides almost frictionless droplet movement. ${ }^{36,37}$ On account of these characteristics, in order to address the biofouling issue, it is proposed to investigate superhydrophobic material as an alternative to the conventional hydrophobic surface.

Only one study reports the fabrication of a fully superhydrophobic (base and cover plate) EWOD device. ${ }^{38}$ This device comprises a silicon dioxide layer coated with perfluorodecyltrichlorosilane that acts both as the dielectric layer and the superhydrophobic actuating surface. Displacement of a water droplet across very short distances at a low voltage of $24 \mathrm{~V}$ was demonstrated but reliable actuation across an operationally relevant distance with this device has not been well evidenced. Another study ${ }^{30}$ reported the partial use of a superhydrophobic surface in a DMF device applied only to the ground (cover) electrode plate instead of the control electrode (base) plate in a 'closed' EWOD configuration. Other studies ${ }^{39-44}$ concerning EWOD superhydrophobic surfaces investigated electrowetting reversibility of CA but did not report fully functional EWOD transportation devices.

All of the studies concerning superhydrophobic surfaces in EWOD devices require expensive equipment and/or involve complex processes that imply high ultimate production costs for large area, potentially disposable, bioassay devices. ${ }^{38-41}$ Mats et $a .^{35}$ investigated some aspects of the application of the commercial superhydrophobic material Ultra-Ever Dry® in a non-EWOD magnetic actuation based DMF device but only reported the roll-off angle required to move magnetic particle suspension droplets. The superhydrophobic surface was prepared by the simple spray-deposition process using a chromatography sprayer. Freire \& Tanner $^{45}$ employed a superamphiphobic (repels both water and oil) surface to develop a DMF device capable of moving bovine serum albumin at concentration 2000 times higher than previously reported without using any additives. This device however relies on contactless dielectrophoresis mechanisms for droplet actuation (termed field dewetting) rather than EWOD hence relying on free-rolling of the droplet rather than wetting mechanisms.

The main aim of the present study is to realise an antibiofouling DMF device by exploiting the self-cleaning property of superhydrophobic surfaces. In the following, the use of a commercially available superhydrophobic material NeverWet ${ }^{\circledR}(\mathrm{NW})$ as actuating surfaces on the base electrodes of a DMF device is examined. Employing such superhydrophobic material offers the potential for four advantageous aspects: (1) fabrication of a parallel-plate device with a passive cover plate; (2) simpler fabrication process compared to the nanofabricated superhydrophobic surfaces presented in previous studies; (3) 
low material cost (as a rough estimation, NeverWet ${ }^{\circledR}$ is 20 times cheaper than Cytop ${ }^{\circledR}$ ); (4) reduction of biofouling compared to hydrophobic surfaces such as Teflon ${ }^{\mathrm{TM}} \mathrm{AF}$ and Cytop ${ }^{\circledR}$.

In this paper, the electrowetting performance of proteinloaded droplets on NW coating is characterised and compared to the performance on Cytop ${ }^{\circledR}$. The impact on the biofouling rate of the electrowetting voltage and the duration of the experiment is then discussed. Finally, a fully-superhydrophobic DMF device is presented and used to demonstrate repeated and reliable actuation of protein-loaded droplets.

\section{Experimental}

\section{Hydrophobic and superhydrophobic surface preparation}

For the contact angle, roll-off angle and protein adsorption measurements, all the test surfaces are first prepared for deposition of the superhydrophobic and hydrophobic layers by coating the substrates with a $3.2 \mu \mathrm{m}$ dielectric layer of ParyleneC (Specialty Coating Systems) using a SCS Labcoater® 2 Parylene Deposition System. Silicon wafer (p-type, $\langle 100\rangle, 1-10$ $\mathrm{ohm} \mathrm{cm}$, Pi Kem Ltd) are used as substrates for all experiments except for the protein adsorption tests for which ITO coated glass microscope slides (Diamond Coatings) are used.

Three distinct surfaces are investigated: one hydrophobic, coated with Cytop ${ }^{\circledR}$ (Asahi Glass Co., Ltd.) and two superhydrophobic, coated using two different deposition processes of the commercial product NeverWet ${ }^{\circledR}$ (Rust-Oleum Corp.). NW is (in standard use) a two-part coating system comprising a base coat and top coat. The base coat is composed of liquefied petroleum gas, aliphatic hydrocarbon, $n$-butyl acetate, methyl isobutyl ketone, methyl acetate, ethyl acetate, and polypropylene while the top coat contains acetone, propane, $n$ butane, and silicone derived ingredients. ${ }^{46}$

For the preparation of the hydrophobic surface, Cytop ${ }^{\circledR}$ is spin coated on top of the Parylene-C layer at $1500 \mathrm{rpm}$ for $30 \mathrm{~s}$ and then soft baked for 30 minutes at $140{ }^{\circ} \mathrm{C}$. To implement the superhydrophobic surfaces, one is coated with top coat NW only (identified as TNW) and the other is coated with both base coat NW and top coat NW (identified as BTNW). Both base and top coat layers are aerosol sprayed between $15 \mathrm{~cm}$ and $30 \mathrm{~cm}$ from the substrate as specified by the manufacturer. Both the base \& top coated surface types are allowed to dry at ambient room temperature for 30 minutes before the second coating is applied. All surfaces are allowed to rest for a minimum of 30 minutes before use.

\section{Droplet solutions}

The impact of biofouling on the electrowetting performances of the different surfaces is assessed using two different proteins, albumin from chicken egg white (ovalbumin), a globular protein of approximately $45 \mathrm{kDa}$ molecular weight, and fibrinogen, a large elongated 'sticky' serum protein of approximately $340 \mathrm{kDa}$ frequently used to measure the adsorption resistance of surfaces. ${ }^{47-49}$

Six solutions are employed: deionised (DI) water $\left(0.1 \mu \mathrm{S} \mathrm{cm}^{-1}\right.$ at $25{ }^{\circ} \mathrm{C}$ ), ovalbumin (lyophilised powder, $\geq 98 \%$, Sigma
Aldrich) solution at three concentrations $\left(0.01 \mathrm{mg} \mathrm{ml}^{-1}, 0.1 \mathrm{mg}\right.$ $\mathrm{ml}^{-1}$ and $1 \mathrm{mg} \mathrm{ml}^{-1}$ ), and fluorescent dye-labelled fibrinogen solution (fibrinogen from human plasma, Alexa Fluor ${ }^{\mathrm{TM}} 647$ Conjugate, ThermoFisher Scientific) at $0.1 \mathrm{mg} \mathrm{ml}^{-1}$.

To assess merging and mixing on the superhydrophobic device, red dyed droplets are prepared from a solution containing $5 \mathrm{mg} \mathrm{ml}^{-1}$ New Cocccine dye (Sigma-Aldrich).

\section{Surface characterisation}

The surfaces are characterised using a scanning electron microscope (JCM 5700, JEOL, USA) and a stylus surface profilometer (AlphaStep ${ }^{\circledR}$ D-500, KLA Tencor).

\section{Contact angle measurements}

The measurement of the CA as a function of applied voltage is performed using a Theta Lite optical tensiometer (Biolin Scientific). A positive potential varying between $0 \mathrm{~V}$ and $250 \mathrm{~V}$ using a DC power supply (Digimess) is applied to a droplet sitting on the prepared silicon substrate via a platinum wire. The volume of the droplet used for the CA measurement is $20 \mu \mathrm{l}$. Extrand \& Moon $^{50}$ suggest the use of small droplets (below $5 \mu \mathrm{l}$ ) for CA measurement on superhydrophobic surface as a larger volume causes the underestimation of CA measurement due to gravity. However, it was experienced during the present study that the inclusion of the wire for the application of potential using volume smaller than $10 \mu \mathrm{l}$ caused underestimation (tens of degrees) of the CA. Droplets with volume below $10 \mu \mathrm{l}$ tend to stick to the wire, altering their shape and sometimes staying suspended above the surface due to the adhesive force on the wire and the high superhydrophobicity of the surface. This is especially true for droplets with high protein concentration. The small volume droplets are also too highly affected by evaporation to suit the long duration of voltage application. Therefore, despite the apparent CA being slightly affected by gravity, larger $20 \mu \mathrm{l}$ droplets were chosen for the present study.

Images of the droplet are recorded at $1.3 \mathrm{fps}$ and the CA evolution is analysed by One Attension software (the Theta Lite system's software). The CA is recorded at every $10 \mathrm{~V}$ increment and once the maximum value of $250 \mathrm{~V}$ was reached the voltage was returned back to zero in $10 \mathrm{~V}$ decrements: thus completing a hysteresis cycle which took 765 seconds to complete. This process is repeated a minimum of three times $(n=3)$ for each droplet solution on each type of surface. Every run is performed with a fresh droplet on a different surface location to prevent the possibility of charge trapping and protein adhesion effects.

\section{Roll-off angle measurements}

The tilting angle of the silicon substrate required to cause a 20 $\mu \mathrm{l}$ droplet to roll-off from its resting position is measured by positioning half of the silicon substrate on a static reference surface while the other half is attached to a small laboratory jack. The jack is carefully levelled with the reference surface before the silicon wafer is placed at the centre. The silicon wafer is then tilted slowly by gradually lowering the jack until the droplet starts to roll-off the surface. The tilt angle of the silicon substrate is measured using a bubble protractor. This process is 
repeated for all four solution types on both types of surface: Cytop ${ }^{\circledR}$ and TNW. To investigate the effect of applied voltage magnitude and the duration of excitation on the roll-off angle, one hysteresis cycles is applied to the droplet prior to measurement. The maximum voltage value and the completion duration of each cycle are varied. Voltage of $0 \mathrm{~V}, 150 \mathrm{~V}$ or $250 \mathrm{~V}$ are used, each with two different completion duration $75 \mathrm{~s}$ or $765 \mathrm{~s}$. The increment of voltage from zero to the maximum value was performed similarly to the method used for CA measurement.

\section{Evaluation of the biofouling rate}

In order to further investigate the effect of applied voltage magnitude and its duration on the biofouling rate, direct measurement of the amount of protein adsorbed onto Cytop® or TNW coated surfaces was made using the same electrowetting hysteresis cycles used for the roll-off angle experiment. The surfaces were exposed to $20 \mu \mathrm{l}$ droplets loaded with $0.1 \mathrm{mg}$ $\mathrm{ml}^{-1}$ of fibrinogen Alexa Fluor ${ }^{\circledR} 647$ conjugate. The relative amount of protein adsorbed the surface of the slides following their contact with the energised droplets was assessed by measuring the mean fluorescence intensity of the resulting spots using a GenePix 4000B microarray scanner (Molecular Devices) (635 $\mathrm{nm}$ excitation laser and Cy5 compatible emission filter, a resolution of $10 \mu \mathrm{m}$ and a PMT gain 500). Image acquisition and analysis was performed using the GenePix® Pro 7 Acquisition and Analysis Microarray software (Molecular Devices).

\section{Design, fabrication and testing of superhydrophobic EWOD DMF device}

To evaluate linear actuation of droplets, DMF test base plates, shown in Fig. 1, are realised. Each plate comprises ten parallel rows of sixteen independent chrome-on-glass control electrodes

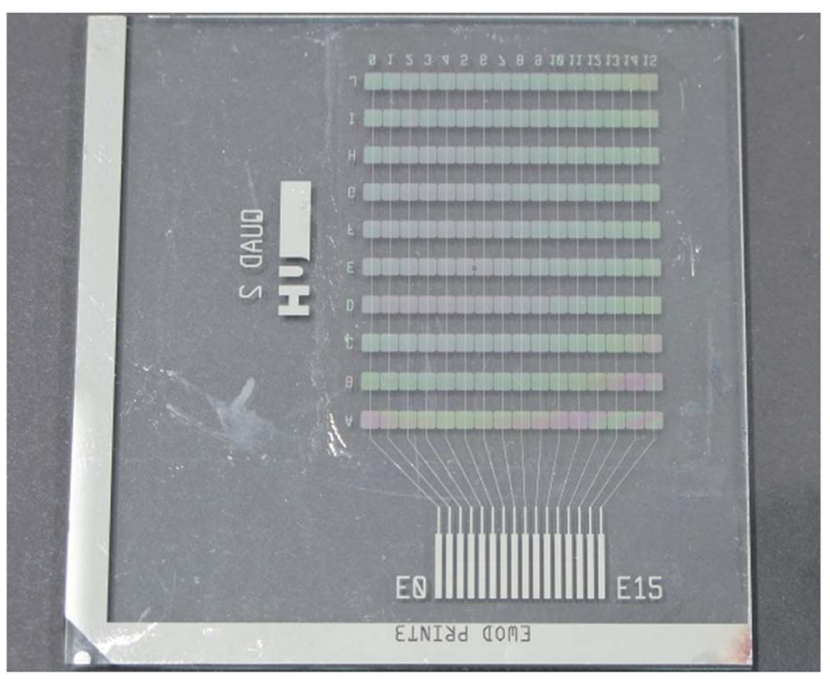

Fig. 1 Test base plate. Each electrode of a row is electrically connected to the electrodes of the same column. In order to provide optical transparency of the $\mathrm{Cr}$ patterned electrodes, each one of them is constituted of fine, lattice-like, dashed $\mathrm{Cr}$ lines. buried underneath a $3.2 \mu \mathrm{m}$ layer of Parylene-C. Each electrode in a row is electrically connected with its corresponding electrodes in the same column of the other rows. Commercial $\mathrm{Cr}$ photomasks implementing our design are supplied by Compugraphics International (Glenrothes, Scotland) to be sawn into quadrants and used directly as the glass plate and the $\mathrm{Cr}$ electrodes of the base. The width of each square control electrode on the base plate is $1.7 \mathrm{~mm}$ with a $60 \mu \mathrm{m}$ inter-electrode spacing along the row. In the parallel plate configuration, the cover plate substrate is a low resistivity 4 inch silicon wafer and the gap between the base and cover plates is $380 \mu \mathrm{m}$. TNW is employed as the superhydrophobic layer of the EWOD device. BTNW is not evaluated. As will be discussed subsequently, this choice is motivated by TNW's better electrowetting performance and reversibility when compared with BTNW's. The top coating of NW is sprayed on both the base and cover plates.

Merging and mixing tests are performed using a bespoke design of electrodes encompassing a $2 \times 5$ electrodes mixing region for the base plate.t These tests are performed using a 'closed' EWOD configuration employing an ITO coated glass slide as cover electrode. Other parameters including the $\mathrm{Cr}$ electrode geometries, the gap thickness and the nature and thickness of the technological layers are similar to the one employed for the linear actuation tests.

Each device is mounted in a custom made PMMA frame and electrical connection is made from the base plate using ZEBRA ${ }^{\circledR}$ elastomeric electronic connectors (Fugipoly, Japan) to a USB powered compact and simple electronics able to address each of the 16 independent electrical lines with $1 \mathrm{kHz}$ sine wave at voltages up to $225 \mathrm{~V}_{\mathrm{RMS}}$.

Droplet movement is recorded using a ScopeTek (Hangzhou Scopetek Opto-Electric Co., Ltd.) microscope camera at $30 \mathrm{fps}$. The displacement and velocity of the droplet on the EWOD devices is measured using image analysis software (Tracker, Video Analysis and Modelling Tool).

\section{Results and discussion}

\section{Surface characterisation}

A surface's superhydrophobicity is determined by both its chemical composition and its topography. ${ }^{42}$ NW surfaces are superhydrophobic due to their hydrocarbon and silicone content. ${ }^{46}$ The two kinds of NW surfaces in this study, TNW and BTNW, are imaged using the SEM. As Fig. 2 shows, at the macroscale $(\times 40$ magnification) BTNW and TNW surfaces display distinct topographies, the BTNW surface displays asperities with dimensions in the hundreds of micrometre range (Fig. 2a) whereas only smaller asperities (in the tens of micrometres range) are observed on the TNW surface (Fig. 2d).

Macro-scale observation reveals a rather homogeneous distribution of the morphological features. It is believed that substantially spherical filler-particles are incorporated into the NeverWet ${ }^{\circledR}$ base and top coating compositions to develop

$\ddagger$ The base plate used for the mixing and merging tests was produced as part of a project (concluded in 2015) funded by the defence science and technology laboratory. Only a small proportion of the design is used in the present work. 

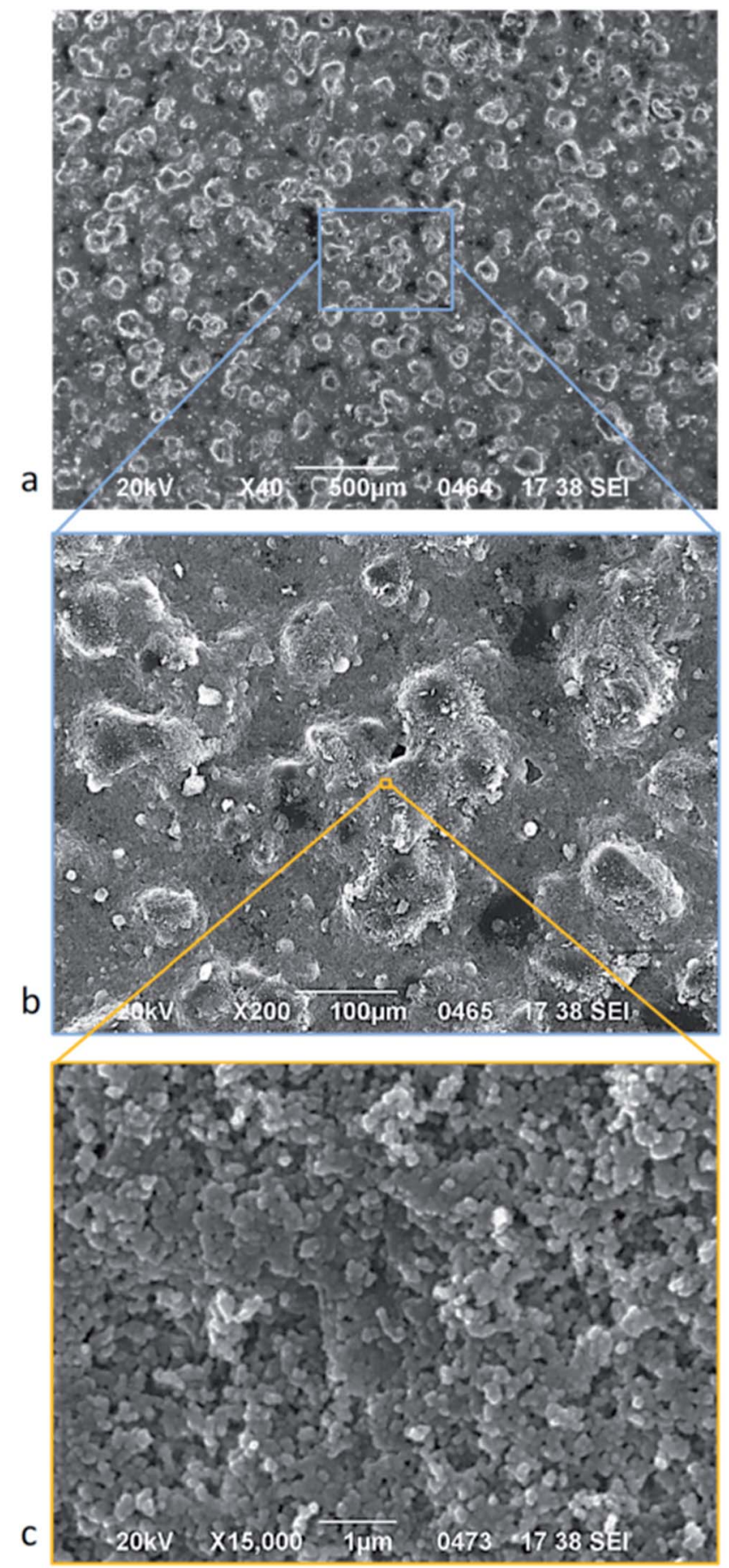
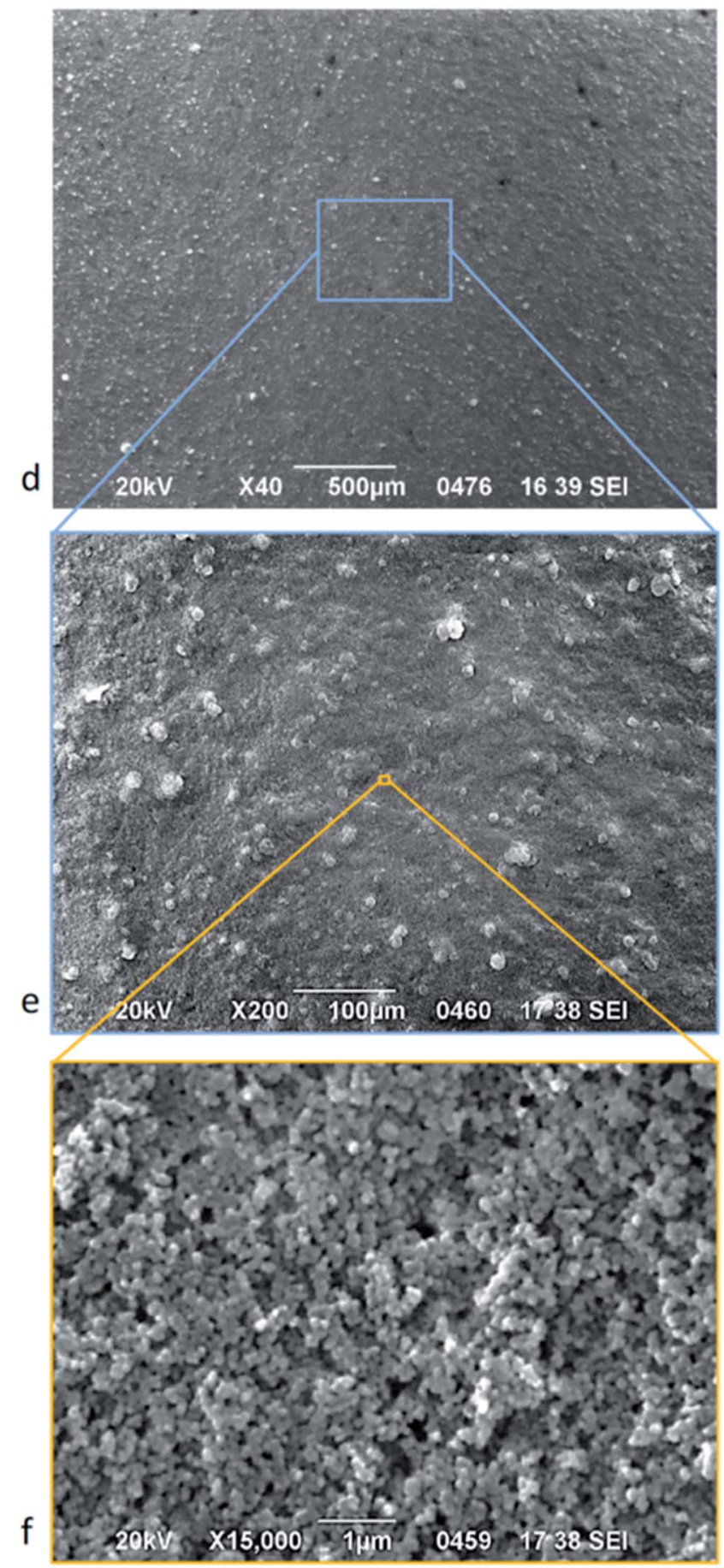

Fig. 2 SEM micrograph of BTNW (left) and TNW (right) surface at different magnifications (increasing magnification from top to bottom): $\times 40$ (a and $d) \times 200$ (b and e) and $\times 15000$ (c and $f$ )

surface texture ${ }^{51}$ comparable to the morphology found at the same scale on lotus leaves and other naturally superhydrophobic surfaces. Higher magnifications (Fig. 2b and e) show the substantially spherical nature of the asperities described above, confirming the probable presence of fillerparticles. It can be seen that the macroscale topography is completed by a nanoscale texturisation.

The highest magnification $(\times 15000)$ reveals the presence of nanometric structures (feature size of circa $100 \mathrm{~nm}$ ) both for
BTNW (Fig. 2c) and TNW (Fig. 2f). The observed nanostructures, very similar in shape and dimension for both surfaces, probably originate from the presence of silicon derivative ${ }^{46}$ in the formulation of NeverWet ${ }^{\circledR}$ top coat as referred to in the material safety data sheet. The presence of both micro and nanoscale structures on both surfaces is consistent with the hierarchical structure as described by Wang \& Jiang ${ }^{37}$ which is critical to the Lotus effect. 
All the morphological features observed above introduce substantial surface roughness into TNW and BTNW surfaces compared to a more classical hydrophobic coating such as Cytop ${ }^{\circledR}$. The surface roughness of BTNW, TNW and Cytop ${ }^{\circledR}$ surfaces were measured using a stylus profiler. As expected, BTNW, with the larger observed features, has the highest roughness, $R_{\mathrm{a}}=4.922 \mu \mathrm{m}$, of the three samples whereas TNW roughness is lower by one order of magnitude: $R_{\mathrm{a}}=0.563 \mu \mathrm{m}$. Two orders of magnitude below this, Cytop ${ }^{\circledR}$ presents the lowest roughness, $R_{\mathrm{a}}=0.008 \mu \mathrm{m}$ indicating a very flat surface.

Equal volume deionised (DI) water droplets are pipetted onto each of the three surfaces. The contact profiles of the sessile DI droplet on each surface are shown in Fig. 3. As anticipated, the micro and nanostructure introduced by the NeverWet ${ }^{\circledR}$ samples (BTNW and TNW) induced a clear superhydrophobic behaviour. However, with its smoother surface, the Cytop ${ }^{\circledR} \mid \mathrm{DI}$ interface remains hydrophobic (contact angle below $150^{\circ}$ ). It is interesting to note the absence of significant impact on the apparent CA of the different surface topographies of TNW and BTNW despite the large difference in surface roughness.

Finally, the thickness of each layer is estimated using the stylus profiler. Cytop ${ }^{\circledR}$ and TNW layers are very thin (respectively several tens of nanometres and several hundreds of nanometres) whereas the BTWN is very thick: around $30 \mu \mathrm{m}$. According to the Young-Lippmann equation (eqn (1)), it is expected that the electrowetting performance on BTNW will be strongly affected by the layer thickness.

\section{Contact angle measurements}

Surface tension of the liquid-gas interface, $\gamma_{\mathrm{lg}}$ can influence the CA of a liquid on a solid substrate based on the Young's equation (eqn (2)):

$$
\gamma_{\mathrm{sl}}=\gamma_{\mathrm{sg}}-\gamma_{\mathrm{lg}} \cos \theta_{\mathrm{c}}
$$

where $\gamma_{\mathrm{sg}}$ is the solid surface free energy and $\gamma_{\mathrm{sl}}$ is the solidliquid surface tension. Although $\gamma_{\mathrm{lg}}$ was not directly measured for all the solutions used here (DI water,
$0.01 \mathrm{mg} \mathrm{ml}^{-1}, 0.1 \mathrm{mg} \mathrm{ml}^{-1}$ and $1 \mathrm{mg} \mathrm{ml}^{-1}$ ovalbumin), the different concentrations of protein lead to different $\gamma_{\mathrm{lg}}$ of the droplet as evidenced by the differing initial CA between the different solutions on all types of surfaces. However, these differences are minor with initial CA values measured between $168^{\circ}$ and $171^{\circ}$ on TNW, between $161^{\circ}$ and $171^{\circ}$ on BTNW and between $97^{\circ}$ and $110^{\circ}$ on Cytop ${ }^{\circledR}$ where it is most pronounced.

The Fig. 4 shows the electrowetting response of all the solutions on the three different surfaces by applying DC voltage between $0 \mathrm{~V}$ to $250 \mathrm{~V}$.

Electrowetting reversibility highly influences the ability of a droplet to move across a surface by means of electrowetting force. All types of droplet display partial reversibility with moderate hysteresis on the TNW surface (Fig. 4). Only TNW displays reversibility for $1 \mathrm{mg} \mathrm{ml}^{-1}$ ovalbumin. On this surface, DI water has the lowest hysteresis of $37^{\circ}$ followed by increasing values for increasing ovalbumin concentrations. On the Cytop ${ }^{\circledR}$ surface, partial reversibility is observed for all solutions excepting $1 \mathrm{mg} \mathrm{ml}{ }^{-1}$ ovalbumin. Only DI water is reversible on the BTNW surface.

The TNW surfaces also allow a wider CA modulation range for all types of droplet solution when compared with Cytop®. For DI water droplets on TNW, the CA decreases by $72^{\circ}$ compared to a CA decrease of $33^{\circ}$ for Cytop ${ }^{\circledR}$. As predicted, BTNW has the poorest electrowetting performance: with a decrease of only $23^{\circ}$ from the initial CA. Cytop ${ }^{\circledR}$ produces the lowest hysteresis for all types of droplet solution among the three surfaces (Fig. 4). Despite TNW's higher hysteresis values than Cytop®, the final CAs on TNW after completing an electrowetting cycle are still higher than the initial CAs on Cytop®. Specifically, the lowest final CA on TNW is $120^{\circ}$ for $1 \mathrm{mg} \mathrm{ml}^{-1}$ ovalbumin which is still higher than the highest initial CA of $110^{\circ}$ for DI water on Cytop ${ }^{\circledR}$ before an electrowetting cycle. TNW's higher hysteresis values than Cytop ${ }^{\circledR}$ have been demonstrated not to affect the droplet actuation performance in EWOD device as supported by the results presented subsequently. It is emphasised that Cytop ${ }^{\circledR}$ is also non reversible for high concentration protein solution suggesting biomolecules

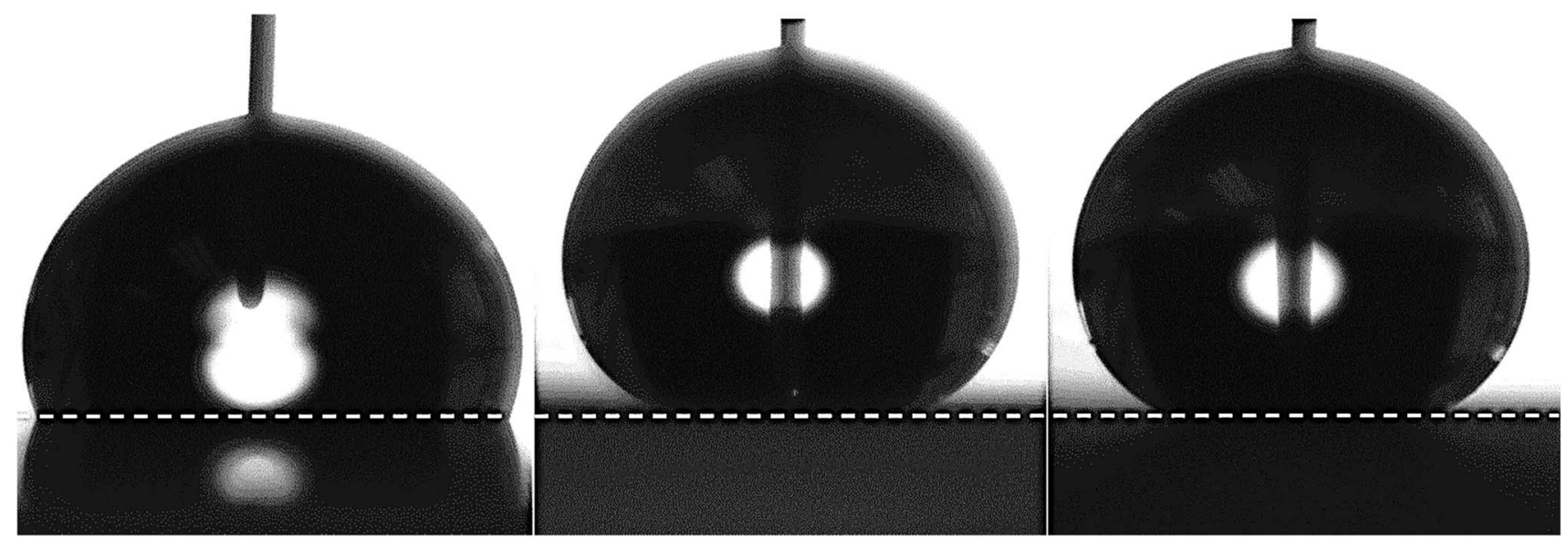

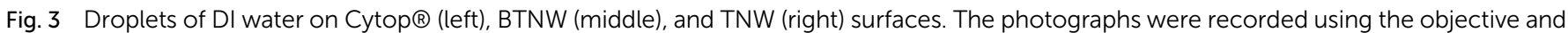
camera of the optical tensiometer. The dash line represents the baseline used for the estimation of the contact angle. 

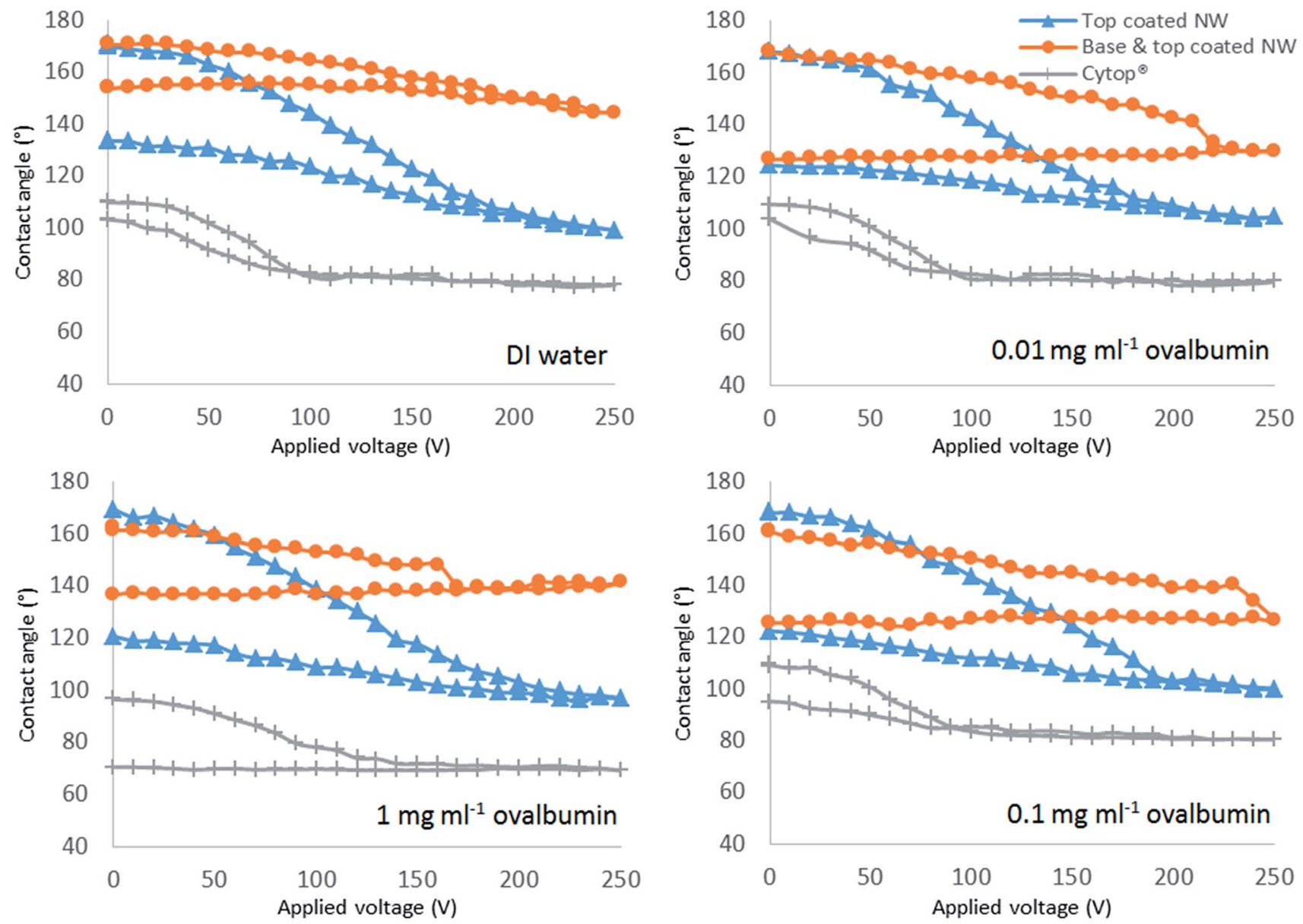

Fig. 4 Contact angle modification vs. the applied voltage for different droplets: (clockwise from top left) $\mathrm{DI}$ water, $0.01,0.1$, and $1 \mathrm{mg} \mathrm{ml}^{-1}$ ovalbumin. Electrowetting hysteresis is plotted for different surfaces: TNW (blue triangles), BTNW (orange circles) and Cytop ${ }^{\circledR}$ (grey crosses). For each hysteresis curve, the starting point is at the higher contact angle.

adhere to the surface, which is the issue this study attempts to examine.

The higher value of hysteresis measured on TNW when compared to Cytop ${ }^{\circledR}$ is considered to be due to the impalement of droplets on the nanostructures of the superhydrophobic surface. Initially, when no electrowetting force is applied, the droplet is located on top of the nanostructures in the CassieBaxter energy state. When a certain voltage level is reached there is a transition to the Wenzel state where impalement of the droplet on to the nanostructures occurs. Once this happens, the energy required for the droplet to transition back to CassieBaxter state is too high and hence the droplet remains partially impaled in the nanostructure resulting in higher values of hysteresis. Although most of the droplet solutions were partially reversible on TNW, their high initial CA could not be repeated. In contrast, Cytop ${ }^{\circledR}$, due to low surface roughness, has lower hysteresis values and an almost fully reversible behaviour. The non-reversibility of all the droplet solutions, except for DI water on BTNW, might also be explained by the same irreversible transition of states from Cassie-Baxter to Wenzel. As BTNW has the highest surface roughness of the three surfaces, indicating the highest nanostructures, it will reasonably require higher transition energy than TNW. Lapierre et al. ${ }^{39}$ previously demonstrated that superhydrophobic surface reversibility decreases with increase in the nanostructure height. They achieved almost complete CA reversibility back to $160^{\circ}$ from $130^{\circ}$ using $190 \mathrm{~V}_{\text {TRMS }}$ on superhydrophobic surface with $20 \mu \mathrm{m}$ long silicon nanowires.

It can be noted that the electrowetting numbers ( $\eta$ in eqn (1)) of the two super-hydrophobic surfaces are significantly different. While the curves of CA modulation for TNW and Cytop ${ }^{\circledR}$ observed in the first half of the hysteresis cycle are almost superimposable, denoting a similar electrowetting number, the CA modulation curve for BTWN is noticeably different. This difference between TNW and BTNW is believed to be mainly contributed by the difference in thickness. While TNW is relatively thin (several hundreds of nanometres), BTNW, due to the presence of the basecoat, is very thick (circa $30 \mu \mathrm{m}$ ), which greatly affects the electrowetting force in the actuating surface corresponding to a lower electrowetting number. There are no significant differences in the electrowetting number between the different types of solution on the same type of surface as there are only small variations in their values of liquid-gas surface tension expect for the $1 \mathrm{mg} \mathrm{ml}^{-1}$ 
ovalbumin solution on Cytop ${ }^{\circledR}$ for which the number appears smaller maybe due to the stickiness of the liquid to the surface. The roughness of the surfaces is another factor affecting the electrowetting mechanism. Alternative models proposed by Hebertson et al. $^{43}$ and Torkelli ${ }^{52}$ take into account the nanostructures' geometry but these approaches were not employed as their approximations need parameters such as the nanostructures' height and diameter which were not measured in this study.

In order to evaluate the impact of maximum voltage on the reversibility of droplet solutions on the TNW surface, the maximum applied voltage was reduced to $150 \mathrm{~V}$ (from $250 \mathrm{~V}$ ) and it was observed that hysteresis reduced by almost $27 \%$ for ovalbumin $0.01 \mathrm{mg} \mathrm{ml}^{-1}$ and $1 \mathrm{mg} \mathrm{ml}^{-1}$. However the decrease was not as significant for DI water. The findings are summarised in Fig. 5. Despite hysteresis being reduced, complete reversibility is still not achievable and furthermore, due to the lower voltage range, the modulation range of CA is reduced accordingly. The maximum allowable voltage for complete reversibility for all four types of solution on TNW surface was found to be between $45 \mathrm{~V}$ to $50 \mathrm{~V}$. Above this voltage, the hysteresis for the CA is larger than $0.5^{\circ}$.

Hysteresis increases with the protein concentration on both Cytop® and TNW surfaces although it is more pronounced on Cytop ${ }^{\circledR}$. Fig. 5 also details the effect of voltage duration on on CA on Cytop ${ }^{\circledR}$. The initial experiments were repeated with a shorter energisation cycle (shorter increment period). The voltage was increased from $0 \mathrm{~V}$ to $250 \mathrm{~V}$ in 30 seconds and decreased to $0 \mathrm{~V}$ in less than 45 seconds. The hysteresis was reduced, especially for the higher protein concentration solutions. This suggests that higher protein concentration solutions are more prone to biofouling and hence are more likely to stick to the surface. In contrast to the non-reversibility of $1 \mathrm{mg} \mathrm{ml}^{-1}$ ovalbumin on Cytop observed during the long (765 seconds) energisation cycle, it was partially reversible when a shorter duration energisation cycle (75 seconds) was used. This finding suggests that Cytop is more susceptible to biofouling than TNW when in prolonged contact with protein solution. This is particularly important as some immunoassay protocols can require long incubation times thus increasing the risk of biofouling. The results from Fig. 5 also imply that the higher the protein concentration, the more impact the duration of voltage application has on CA reversibility and hysteresis. This indicates that the protein adhesion on the hydrophobic/ superhydrophobic surface is highly time dependent as suggested elsewhere. ${ }^{53}$

CA modification as a function of voltage can be predicted by the Young-Lippmann equation (eqn (1)) until saturation occurs; beyond the saturation voltage, the CA, reaching the saturation angle value, cannot be reduced further. Studies ${ }^{54-56}$ suggest that the saturation angle is approximately $60-70^{\circ}$ for any electrowetting systems. The physical mechanisms of saturation are not fully understood, but Chevalliot et al. ${ }^{55}$ suggest factors that could affect this phenomenon. Comparing the results presented in Fig. 4 with earlier studies, ${ }^{54-56}$ saturation is found to occur at CAs higher than the $60-70^{\circ}$ range: $96-104^{\circ}$ for TNW, $125-145^{\circ}$ for BTNW, and $69-80^{\circ}$ for Cytop ${ }^{\circledR}$. Only $1 \mathrm{mg} \mathrm{ml}^{-1}$ ovalbumin on Cytop ${ }^{\circledR}$ has a saturation angle within the $60^{\circ}$ to $70^{\circ}$ range. The saturation point for Cytop ${ }^{\circledR}$ occurred at around $100 \mathrm{~V}$ for all types of solution.

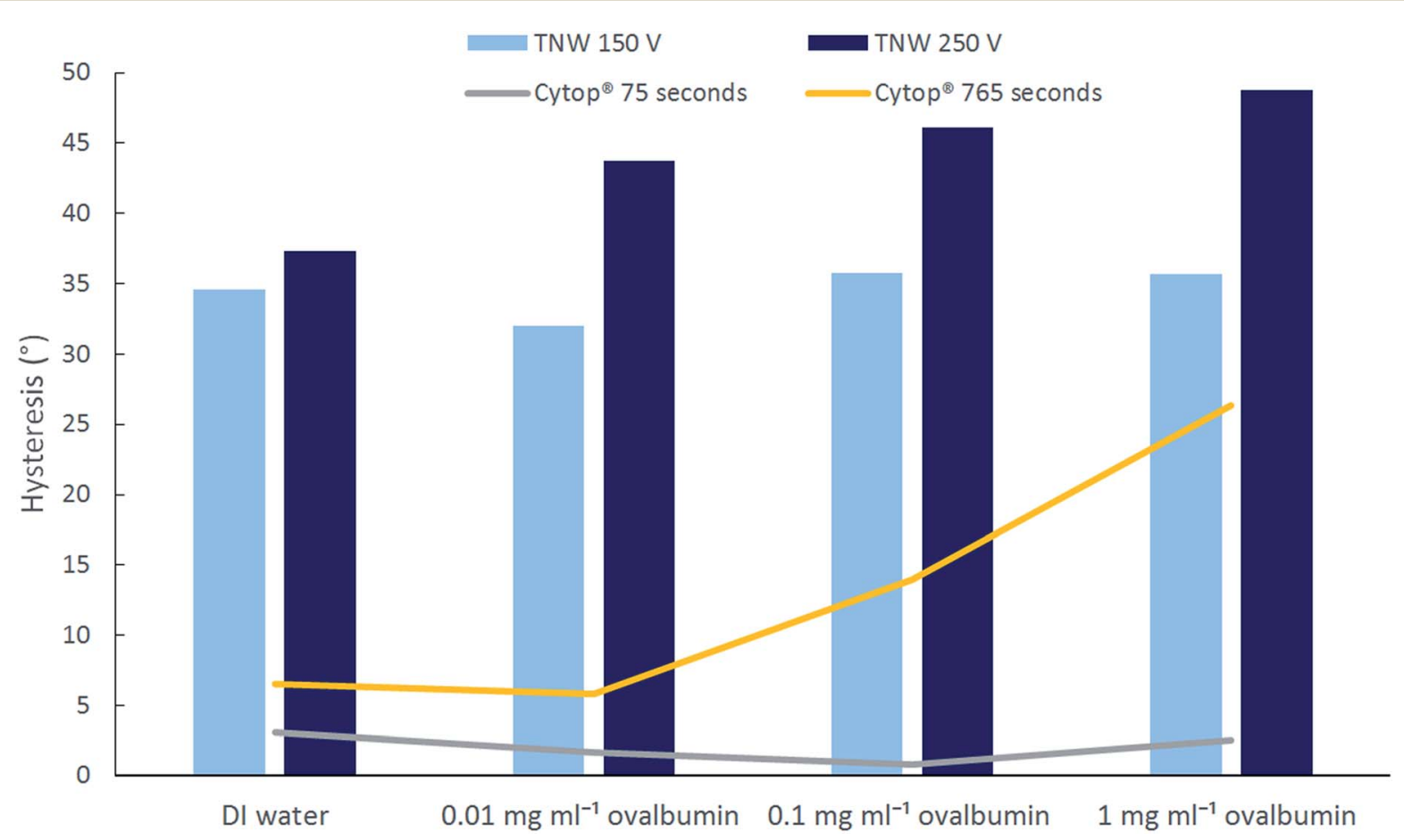

Fig. 5 Hysteresis of different solutions on TNW for $150 \mathrm{~V}$ and $250 \mathrm{~V}$ maximum applied voltage (column graphs) and on Cytop ${ }^{\circledR}$ for long and short duration application of $250 \mathrm{~V}$ (line graphs). 
The disparity between the saturation angle results in this study and those reported elsewhere are somewhat surprising but may be due to the longer duration of voltage application prior to reaching saturation voltage in the present case. Both Chevalliot et al. and Quinn et al. have clearly demonstrated that CA saturation is highly time-dependent. ${ }^{54,55}$ When the experiments were repeated with a shorter energisation cycle for the Cytop surface, the saturation angles for all solutions ranged from $60^{\circ}$ to $70^{\circ}$, lower than in the first experiment, thus confirming the effect of voltage exposure duration on saturation angle. Although not fully understood, an explanation is proposed by Chevaliot et al. ${ }^{55}$ who imply that dielectric charging of the insulating layer causes a diminution of the electric field at the liquid-solid interface. As a result, the electrowetting force is reduced and the saturation angle is increased.

Of the three types of surface, BTNW has the lowest CA changes resulting in the highest saturation angles for all the protein solutions while the DI droplets' saturation is not reached. As discussed by Chevalliot et al., the nature of the hydrophobic surface plays a role in CA saturation. TNW appears to promote dielectric charging more than Cytop ${ }^{\circledR}$. It is considered that BTNW layer, like TNW will suffer from the cumulative effect of dielectric charging introduced by the top coat and the poor electrowetting performance due to the thickness of the base coat as supported by its very small CA changes. In addition, the protein solutions behave differently than on the other two surfaces. Droplets of all three concentrations of ovalbumin reach saturation at different voltages and very high angles: $127^{\circ}$ for $0.01 \mathrm{mg} \mathrm{ml}^{-1}$ at $220 \mathrm{~V}, 125^{\circ}$ for $0.1 \mathrm{mg} \mathrm{ml}^{-1}$ at $240 \mathrm{~V}$, and $137^{\circ}$ for $1 \mathrm{mg} \mathrm{ml}^{-1}$ at $170 \mathrm{~V}$. These saturation values do not substantially fluctuate from the initial CA values, especially for ovalbumin $1 \mathrm{mg} \mathrm{ml}^{-1}$ where it differs by only $26^{\circ}$.

Another interesting observation regarding the behaviour of protein solutions on BTNW concerns the discontinuity, or the sudden drop, of CA that occurs before reaching the saturation point as can be seen from the Fig. 4 . It seems that once a certain voltage is reached, a significant change in the CA is induced by the abrupt impalement of the droplet. This does not occur on TNW where the changes in the CA are gradual.

The magnitude of the sudden change is approximately $15^{\circ}$ for both $0.01 \mathrm{mg} \mathrm{ml}^{-1}$ and $0.1 \mathrm{mg} \mathrm{ml}^{-1}$ ovalbumin and $8.5^{\circ}$ for $1 \mathrm{mg} \mathrm{ml}^{-1}$ ovalbumin. The lower CA change for the $1 \mathrm{mg} \mathrm{ml}^{-1}$ ovalbumin droplet could be due to a greater aggregation of protein molecules on the wall of the nanostructure limiting the penetration of the fluid. Further study, beyond the scope of this paper, would be needed to fully characterise this phenomenon. This result, together with the irreversibility of protein solution droplets on this surface, contributed greatly to the decision not to use the NeverWet ${ }^{\circledR}$ base coat product in the fabrication of the EWOD droplet actuator.

\section{Roll-off angle measurements}

The tilting angle required for the TNW and Cytop® surfaces to roll-off a $20 \mu \mathrm{l}$ droplet from its resting position is evaluated. Roll-off angle measurement is a function of the gravitational force required to move a droplet when it is large enough to overcome the static friction force of the droplet on the solid surface. ${ }^{35}$ BTNW is excluded from this particular study at this point in experimentation as the irreversibility of most of the solutions on this surface has discounted its potential as an EWOD actuating surface. The roll-off angle is measured on each surface under different conditions: immediately after pipetting the droplet on the surface, after a $765 \mathrm{~s}$ resting period, or after application of a pre-conditioning voltage (either $150 \mathrm{~V}$ or $250 \mathrm{~V}$ ) for either 75 seconds or 765 seconds.

As can be seen in Table 1, when no voltage pre-conditioning is applied, all concentrations of droplet solution roll-off very easily on TNW regardless of the durations; roll off angle ranges from less than $1^{\circ}$ to $3^{\circ}$. The roll-off angles on TNW are also very low for DI water when the preconditioning voltage is $150 \mathrm{~V}$ for both $75 \mathrm{~s}$ and $765 \mathrm{~s}$ durations. Slight increases in the roll-off angles are observed for DI water when the voltage is increased to $250 \mathrm{~V}$ but there is not much difference between $250 \mathrm{~V}$ applied for $75 \mathrm{~s}$ and $765 \mathrm{~s}$. In this case, the slight increase of the roll-off angle for higher voltage may be due to the impalement of the droplet on the TNW nanostructures. On Cytop ${ }^{\circledR}$, the roll-off angles for DI water are in all cases higher $\left(16-30^{\circ}\right)$ than on TNW. Apart from that, DI water behaves similarly to TNW; the roll-off angle is not influenced significantly by the variations in both pre-conditioning voltage magnitude and duration.

For the protein solution droplets, the roll-off angle on TNW increases with the duration of the pre-conditioning period suggesting molecular biofouling from the droplet to the surface. The roll-off angle increase with time is clearly reinforced by an increase of the pre-conditioning voltage indicating an increase of the biofouling rate. The effect of voltage amplitude and duration on the roll-off angle variation is especially significant when both a high voltage of $250 \mathrm{~V}$ and a long duration of $765 \mathrm{~s}$ are employed. The roll-off angles for settings other than $250 \mathrm{~V}$

Table 1 Measured roll-off angles for different types of droplet solution on TNW and Cytop ${ }^{\circledR}$ surfaces

\begin{tabular}{|c|c|c|c|c|c|c|c|c|c|c|c|c|}
\hline \multirow[b]{2}{*}{ Types of solution } & \multicolumn{6}{|c|}{$\underline{\text { Roll-off angle on top coat NW }\left[^{\circ}\right]}$} & \multicolumn{6}{|c|}{ Roll-off angle on Cytop ${ }^{\circledR}\left[{ }^{\circ}\right]$} \\
\hline & $0 \mathrm{~V}$ & $\begin{array}{l}0 \mathrm{~V} \\
(765 \mathrm{~s})\end{array}$ & $\begin{array}{l}150 \mathrm{~V} \\
(75 \mathrm{~s})\end{array}$ & $\begin{array}{l}150 \mathrm{~V} \\
(765 \mathrm{~s})\end{array}$ & $\begin{array}{l}250 \mathrm{~V} \\
(75 \mathrm{~s})\end{array}$ & $\begin{array}{l}250 \mathrm{~V} \\
(765 \mathrm{~s})\end{array}$ & $0 \mathrm{~V}$ & $\begin{array}{l}0 \mathrm{~V} \\
(765 \mathrm{~s})\end{array}$ & $\begin{array}{l}150 \mathrm{~V} \\
(75 \mathrm{~s})\end{array}$ & $\begin{array}{l}150 \mathrm{~V} \\
(765 \mathrm{~s})\end{array}$ & $\begin{array}{l}250 \mathrm{~V} \\
(75 \mathrm{~s})\end{array}$ & $\begin{array}{l}250 \mathrm{~V} \\
(765 \mathrm{~s})\end{array}$ \\
\hline DI water & $<1$ & $<1$ & $<1$ & $<1$ & $2-4$ & 4 & 20 & 20 & $17-20$ & $19-21$ & $16-21$ & $17-30$ \\
\hline $0.01 \mathrm{mg} \mathrm{ml}^{-1}$ ovalbumin & $<1$ & 3 & $4-5$ & 10 & 4 & $16-24$ & $24-45$ & $>90$ & $32-38$ & $>90$ & $27-28$ & $>90$ \\
\hline $0.1 \mathrm{mg} \mathrm{ml}^{-1}$ ovalbumin & $<1$ & 3 & 3 & 9 & 10 & $20-53$ & $33-50$ & $>90$ & 45 & $>90$ & $33-35$ & $>90$ \\
\hline $1 \mathrm{mg} \mathrm{ml}^{-1}$ ovalbumin & $<1$ & 3 & 4 & 9 & 10 & $20-33$ & $>90$ & $>90$ & $>90$ & $>90$ & $>90$ & $>90$ \\
\hline
\end{tabular}


and $765 \mathrm{~s}$ are generally low with the maximum value of $10^{\circ}$. Comparing the roll-off angle between the droplet solutions, there are substantial increases between the DI water and the protein solutions but there are no significant variations between the different protein concentrations for all precondition settings. Generally, the increase in roll-off angle on TNW can be influenced by two factors: droplet impalement on the TNW microstructures and protein molecule adhesion to the surface. For the first factor, the transition from Cassie-Baxter state to Wenzel state increases the force needed to move the droplet on the surface, thus the higher roll-off angle. The latter factor plays a major role when protein solutions are used and its effect is most pronounced with a both high magnitude and a long duration of applied voltage.

On Cytop ${ }^{\circledR}$, the roll-off angle generally increases with the droplet solution concentration and the voltage duration. The roll-off angle increases significantly to larger than $90^{\circ}$ for all the protein solutions when the duration is $765 \mathrm{~s}$ with or without pre-conditioning voltage and regardless of the magnitude of the latter. The $1 \mathrm{mg} \mathrm{ml}^{-1}$ ovalbumin has roll-off angles larger than $90^{\circ}$ for all pre-condition settings including without resting period. This finding demonstrates how susceptible Cytop ${ }^{\circledR}$ is to molecule adhesion when protein solution is used and this effect is especially enhanced for prolonged duration of contact.

TNW displays much lower roll-off angles than Cytop ${ }^{\circledR}$ for all pre-condition settings and solutions indicating a significantly lower biofouling rate on the superhydrophobic TNW. Direct measurement of the fluorescent intensity of a tagged protein on the surface is used to confirm this finding.

\section{Evaluation of the biofouling rate}

Measurements of the mean fluorescence intensity of spots of labelled protein adsorbed on TNW and Cytop ${ }^{\circledR}$ surfaces are performed following their exposure to $20 \mu \mathrm{l}$ droplets of fibrinogen Alexa Fluor 647 solution at $0.1 \mathrm{mg} \mathrm{ml}^{-1}$ under the same conditions voltage and time periods applied for the roll off angle testing ( $0 \mathrm{~V}, 150 \mathrm{~V}$ and $250 \mathrm{~V}$ for 75 or 765 seconds). The results are shown in Fig. 6a, while an example slide is shown in Fig. 6b.

The results are found to closely mirror those obtained in the roll-off tests (Table 1), with the amount of biofouling observed to be significantly greater on Cytop ${ }^{\circledR}$ than on TNW (Fig. 6a). In the case of the Cytop ${ }^{\circledR}$ surface, there appeared to be little increase in adsorption of protein with increasing voltage but a strong dependence on exposure time. For the TNW surface there is little significant difference in the amount of protein adsorption with exposure time or voltage until $250 \mathrm{~V}$, where the signal more than doubled for the 75 second exposure and increased 4-fold for 725 second exposure, again consistent with the $0.1 \mathrm{mg} \mathrm{ml}^{-1}$ ovalbumin roll-off angle results.

The direct measurement of protein adsorption confirms the promising anti-biofouling behaviour of TNW surfaces. As a result, TNW surfaces are evaluated as the actuation component of a DMF device in both single and parallel-plate configuration.

\section{Realisation and testing of superhydrophobic EWOD DMF devices}

To evaluate the EWOD actuation of a high protein (OVA and fibrinogen) concentration droplet, both single-plate and a)

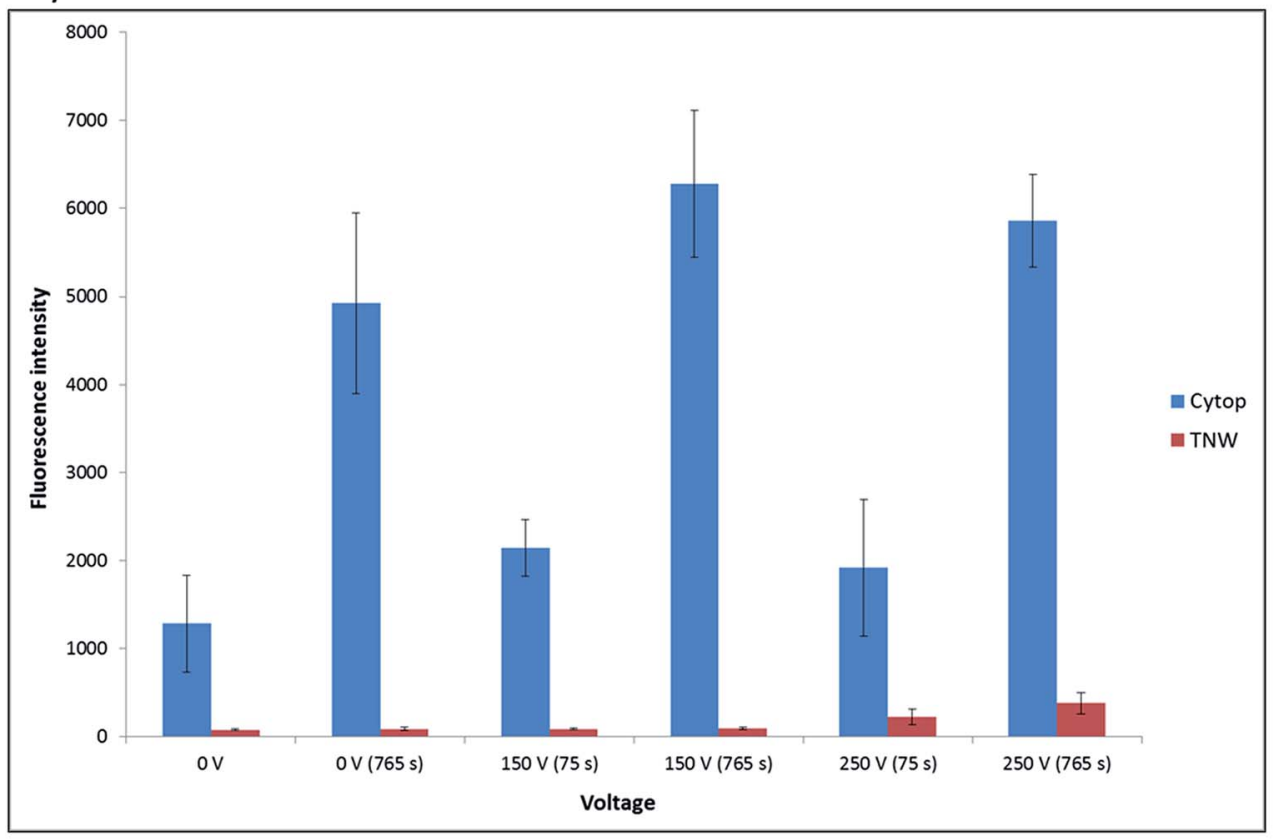

b)

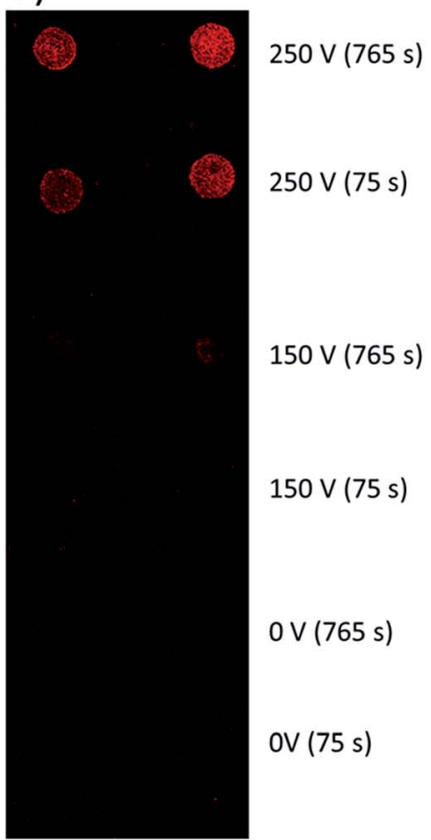

Fig. 6 Comparison of protein adsorption after different electrowetting treatment of a $0.1 \mathrm{mg} \mathrm{ml}^{-1}$ fluorescently tagged fibrinogen droplet. (a) Graph of the fluorescence intensity of adsorbed protein measured on Cytop and TNW following exposure with fibrinogen Alexa Fluor 6470.1 mg $\mathrm{ml}^{-1} 20 \mu \mathrm{l}$ droplets and different applied electric fields and contact times (PMT gain 500). (b) Example slide TNW with adsorbed protein following a similar exposure with fibrinogen Alexa Fluor $6470.1 \mathrm{mg} \mathrm{ml}^{-1} 20 \mu \mathrm{l}$ droplets. 


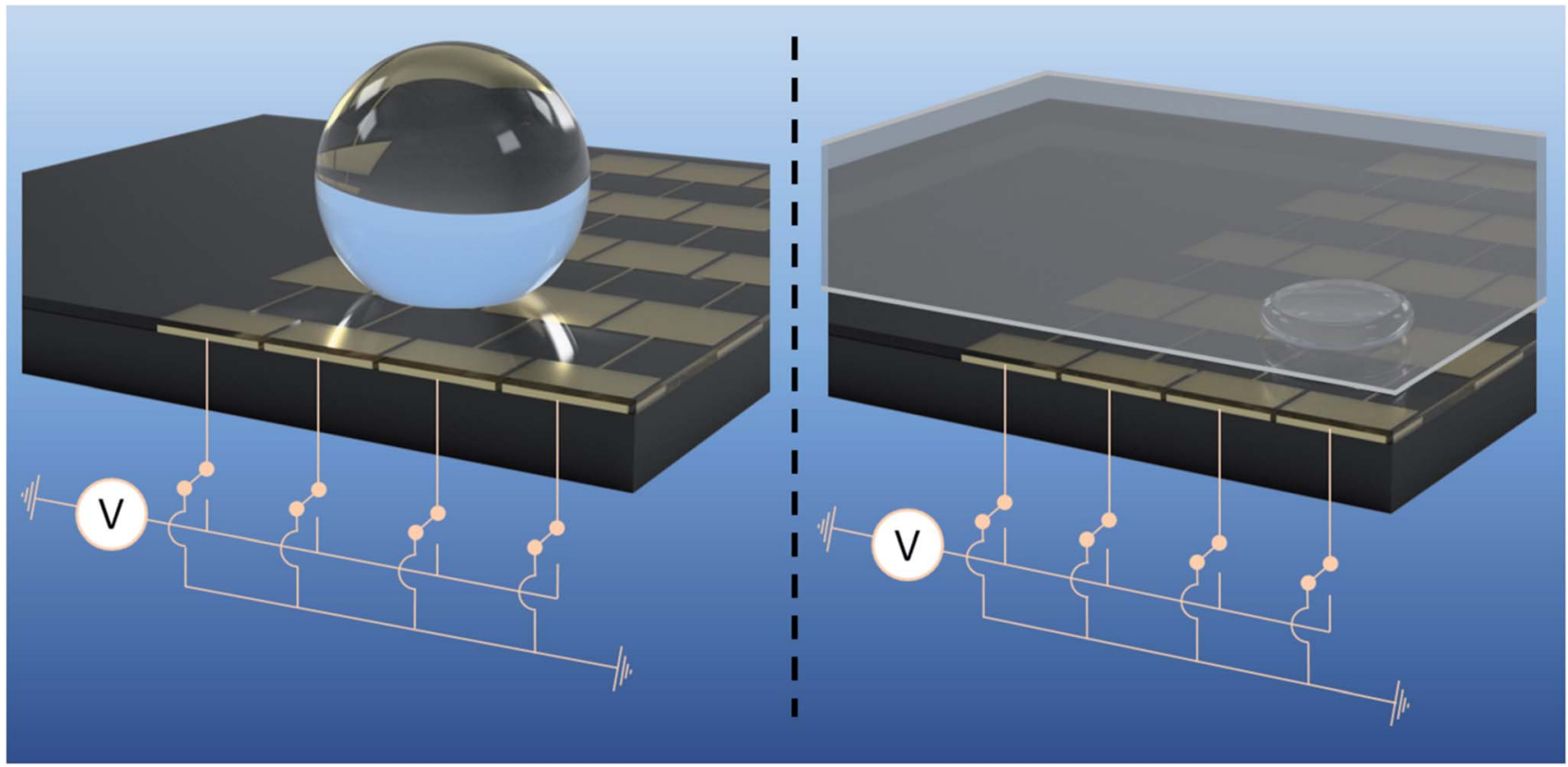

Fig. 7 Illustrative superhydrophobic EWOD device designs and configurations: single-plate (left) and parallel-plate (right). Droplet movement is instigated when sufficient voltage is applied to the control electrodes underneath the droplet. The control electrodes are individually addressed and activated in sequence to dictate the droplet movement.

parallel-plate DMF devices is assembled using the base plate presented in Fig. 1. The two configurations are shown in the Fig. 7; the droplet volumes used in the single-plate and parallelplate configurations are $35 \mu \mathrm{l}$ and $5 \mu \mathrm{l}$ respectively. In each configuration, the droplet is actuated by individually energising electrodes in sequence.

The result of droplet actuation in both single-plate and parallel-plate devices is summarised in the Fig. 8. The singleplate device was tested by actuating $35 \mu \mathrm{l}$ droplets of DI water, $1 \mathrm{mg} \mathrm{ml}{ }^{-1}$ and $10 \mathrm{mg} \mathrm{ml}^{-1}$ ovalbumin and $0.1 \mathrm{mg} \mathrm{ml}^{-1}$ fibrinogen at $150 \mathrm{~V}_{\mathrm{RMS}}$ and $100 \mathrm{~ms}$ pulse rate. The measured displacement and velocity of all types of droplets following an actuation route across seven electrodes and back to their initial position (21.1 mm total travel) are presented. All types of droplet take approximately between 1.7 seconds to 2.6 seconds (the maximum recorded average velocity of droplets is $1.24 \mathrm{~cm} \mathrm{~s}^{-1}$ ) to complete one cycle depending on the driving electronics§ with varying instantaneous velocities. Actuation of concentrations up to $10 \mathrm{mg} \mathrm{ml}^{-1}$ are recorded for ovalbumin droplets in the single plate device, however, at such concentration actuation becomes unreliable as the droplets exhibit sticky behaviour. Droplets in single plate devices are generally found more difficult to control inherently due to the motion mechanisms.

In the single plate device, the EWOD force is the primary actuator of the droplet but instead of being brought to electrical equilibrium between the energised electrode and the zero electric potential electrode, as it is the case for typical

$\S$ The actuation of the $0.1 \mathrm{mg} \mathrm{ml}^{-1}$ fibrinogen droplet was performed using a different version of the drive electronics, which explains the difference in completion time. hydrophobic single plate devices, ${ }^{57}$ the droplet continues rolling onto the energised electrode due to the very low friction on the superhydrophobic device. Actuation is difficult to control using a single plate configuration because of the rolling mechanism described above. Whilst the later allows actuation droplets of higher concentration (actuation of $10 \mathrm{mg} \mathrm{ml}^{-1}$ ovalbumin was only achieved using a single plate configuration and was not successful in the parallel plate device), it can also cause actuation failure either by propelling the droplet farther than excepted or on the contrary, not far enough in the case of sticky droplets or sometimes even sideways (not displayed with the results) and is thus generally unreliable.

As a good example, the $10 \mathrm{mg} \mathrm{ml}^{-1}$ ovalbumin droplet only traveled across six electrodes (and back) as it didn't reach the last electrode due to the stickiness of the droplet but in contrast reached a high maximum instantaneous velocity of $2.42 \mathrm{~cm} \mathrm{~s}^{-1}$. The propelling and rolling mechanisms in the single plate device can cause the droplet to reach high instantaneous velocity at some locations on the device surface as can be seen in the velocity graph for single plate device in the Fig. 8. A video clip showing the $1 \mathrm{mg} \mathrm{ml}^{-1}$ ovalbumin droplet transportation for three consecutive cycles on the single-plate device is available in the ESI (Video $1 \dagger$ ).

The parallel-plate device was tested by actuating $5 \mu \mathrm{l}$ droplets of DI water, $1 \mathrm{mg} \mathrm{ml}^{-1}$ ovalbumin, and $0.1 \mathrm{mg} \mathrm{ml}^{-1}$ fibrinogen at $150 \mathrm{~V}_{\mathrm{RMS}}$ and $100 \mathrm{~ms}$ pulse rate. The measured displacements and velocities of the droplet edge (leading edge in the first half-cycle and trailing edge in the second half-cycle) for DI water, $1 \mathrm{mg} \mathrm{ml}^{-1}$ ovalbumin, and $0.1 \mathrm{mg} \mathrm{ml}^{-1}$ fibrinogen for one cycle are presented in Fig. 8. All types of droplet solutions take approximately between 1.7 seconds to 2.5 seconds to be 


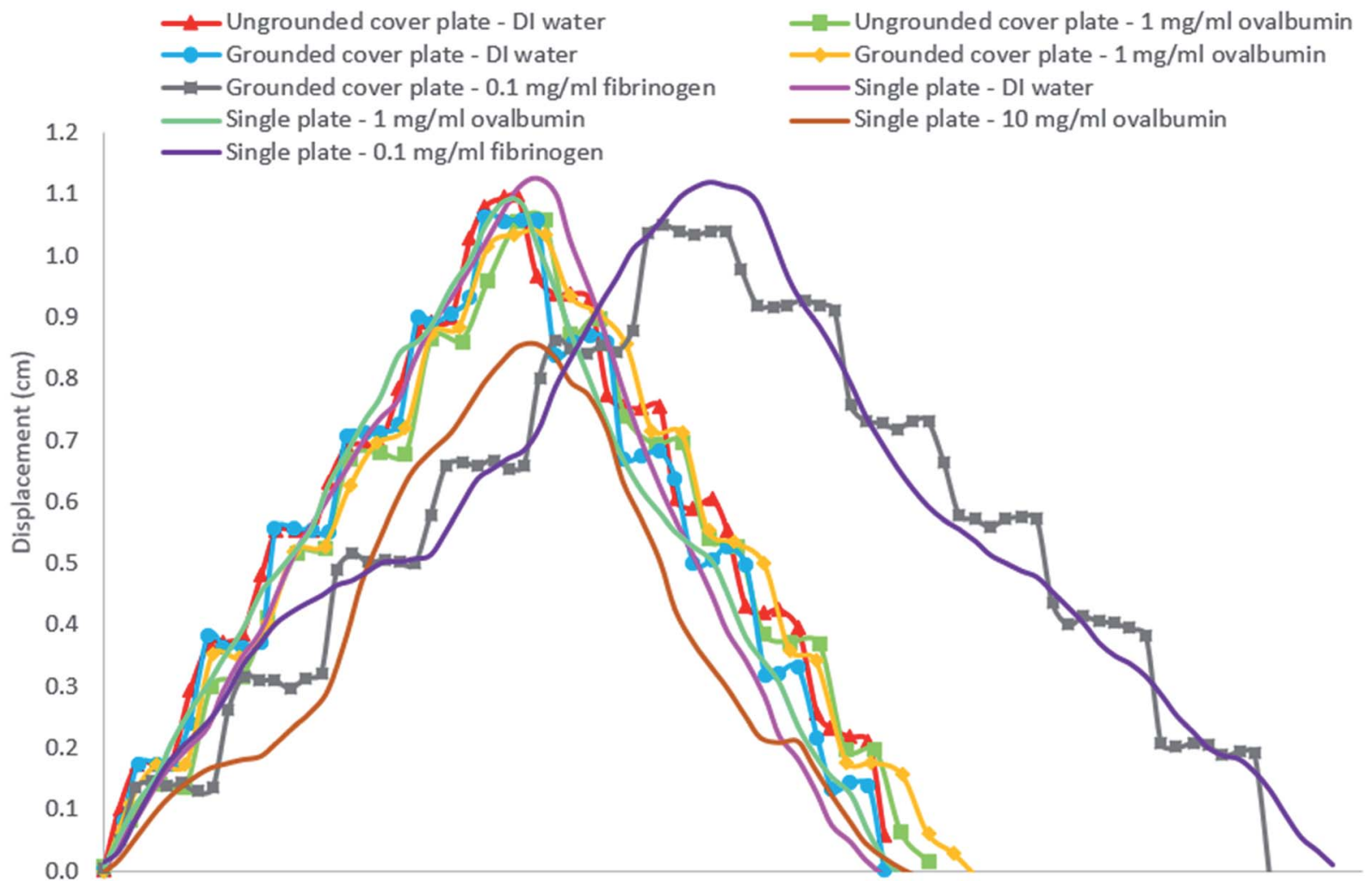

$\begin{array}{lllllllllllllllllllllllllllll}0.0 & 0.1 & 0.2 & 0.3 & 0.4 & 0.5 & 0.6 & 0.7 & 0.8 & 0.9 & 1.0 & 1.1 & 1.2 & 1.3 & 1.4 & 1.5 & 1.6 & 1.7 & 1.8 & 1.9 & 2.0 & 2.1 & 2.2 & 2.3 & 2.4 & 2.5 & 2.6 & 2.7\end{array}$ Time (s)
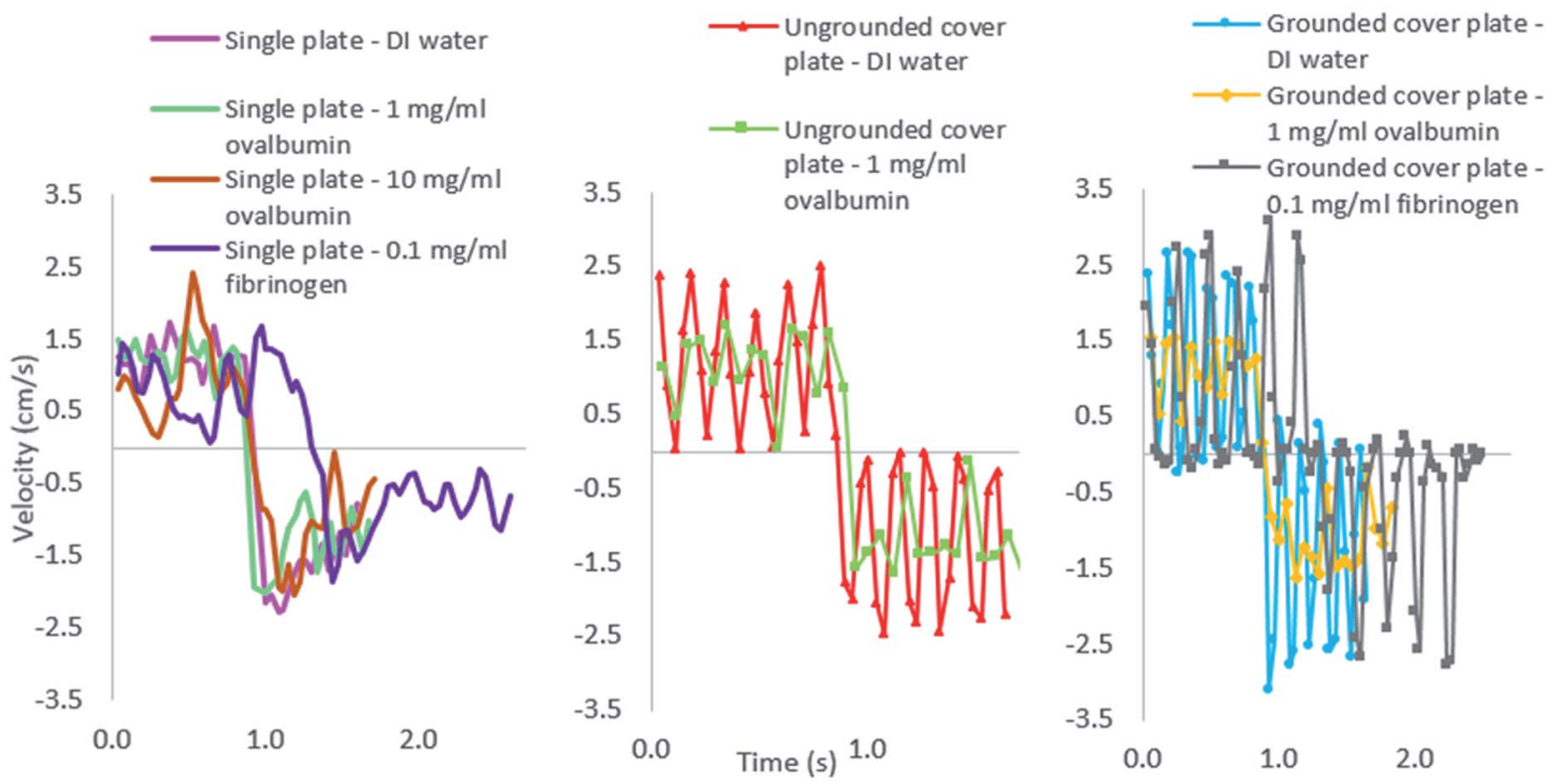

Fig. 8 Displacements and velocities of $5 \mu$ (parallel plate) and $35 \mu \mathrm{l}$ (single plate) of DI water and ovalbumin droplets as a function of time for one cycle using $150 V_{\text {RMS }}$ and 100 ms pulse rate. The top graph shows the displacement of DI water, ovalbumin and fibrinogen droplet solutions on both parallel and single plate configurations. The bottom three graphs from left to right show the instantaneous velocity: of droplets (water, ovalbumin and fibrinogen) in the single plate device; of water and ovalbumin droplets in ungrounded cover plate of the parallel-plate device configuration and of droplets (water, ovalbumin and fibrinogen) in the grounded parallel plate device.

transported across seven electrodes and return to their initial positions, again depending on the driving electronics.§ The rather small variation in instantaneous velocity during droplets' journey can be attributed to the varying quality of the superhydrophobic surface. Some plate surfaces deviate more from uniformity than others and have minute defects that occurred during the spraying process of device fabrication. The DI water droplets reach the highest value of instantaneous velocity with $3.10 \mathrm{~cm} \mathrm{~s}^{-1}$. 
In contrast with the single plate configuration, the parallelplate device displays discrete movement since its displacement measurement is based on the droplet edge, is not able to roll freely because of the resistance by the cover plate inhibiting its momentum. During each electrode activation the DI water and $0.1 \mathrm{mg} \mathrm{ml}{ }^{-1}$ fibrinogen droplets demonstrate higher instantaneous velocities than the $1 \mathrm{mg} \mathrm{ml}^{-1}$ ovalbumin which could be due to the ovalbumin's higher viscosity caused by its higher concentration. Higher viscosity may cause the droplet edge to reach its steady state more slowly, thus affecting its velocity measurement. ${ }^{55}$ However, it is emphasised that in the absence of viscosity measurement, this is just a hypothesis. As mentioned before, Neverwet ${ }^{\circledR}$ is an off-the-shelf commercial product, therefore batch to batch variability in composition leading to varying surface quality is to be expected in the surface quality of the tested devices.

Another configuration of the parallel-plate device using an ungrounded cover plate, is tested. The result comparing between the grounded cover plate with the ungrounded one is summarised in the Fig. 8. Only DI water and ovalbumin are used to test these two configurations. The maximum instantaneous velocities for DI water droplets in ungrounded and grounded cover plate devices are similar: respectively $2.5 \mathrm{~cm} \mathrm{~s}^{-1}$ and $3.10 \mathrm{~cm}^{-1}$. The $1 \mathrm{mg} \mathrm{ml} \mathrm{m}^{-1}$ ovalbumin also has very similar average velocities in ungrounded and grounded cover plate devices (1.69 $\mathrm{cm} \mathrm{s}^{-1}$ and $1.60 \mathrm{~cm} \mathrm{~s}^{-1}$ respectively), albeit significantly lower than for DI water. Video clips showing $1 \mathrm{mg}$ $\mathrm{ml}^{-1}$ ovalbumin droplet transportation for one cycle in both grounded (Video $2 \dagger$ ) and ungrounded (Video $3 \dagger$ ) cover plate devices are available in the ESI. $\dagger$

These results demonstrate the capability of the superhydrophobic device to rapidly and reliably transport a proteinladen droplet. Both single and parallel plate configuration allows reliable transportation of $1 \mathrm{mg} \mathrm{ml}^{-1}$ ovalbumin droplet and $0.1 \mathrm{mg} \mathrm{ml} \mathrm{m}^{-1}$ fibrinogen droplet. The latter is 500 times higher than previously reported concentration of $1.5 \mu \mathrm{g} \mathrm{ml}$ without any pluronic additives. ${ }^{28}$ Protein-laden droplets' actuation performances are comparable to the performance of DI water droplets on previously reported EWOD devices. The single plate device droplet velocity is comparable, albeit lower than, Park et al.' ${ }^{57}$ device, which reached maximum (average) speed of $2.5 \mathrm{~cm} \mathrm{~s}^{-1}$ at $150 \mathrm{~V}_{\mathrm{RMS}}$. In contrast, at the same actuation voltage, average velocity of only around $1.2 \mathrm{~cm} \mathrm{~s}^{-1}$ is demonstrated using our single plate device, however instantaneous velocities of circa $2.5 \mathrm{~cm} \mathrm{~s}^{-1}$ can be achieved. Similarly, for the parallel plate device, Pollack et al. $^{13}$ reported an average droplet velocity of $3 \mathrm{~cm} \mathrm{~s}^{-1}$ using $20 \mathrm{~Hz}$ pulse rate, which is comparable to the average velocities reported here (circa $1.2 \mathrm{~cm} \mathrm{~s}^{-1}$ using $10 \mathrm{~Hz}$ pulse rate).

The parallel plate configuration of the superhydrophobic device is used to merge together one $5 \mu$ droplet of DI water with one $5 \mu \mathrm{l}$ droplet of New Coccine dye solution. As can be seen on the Fig. 9, the DI water droplet is actuated towards the

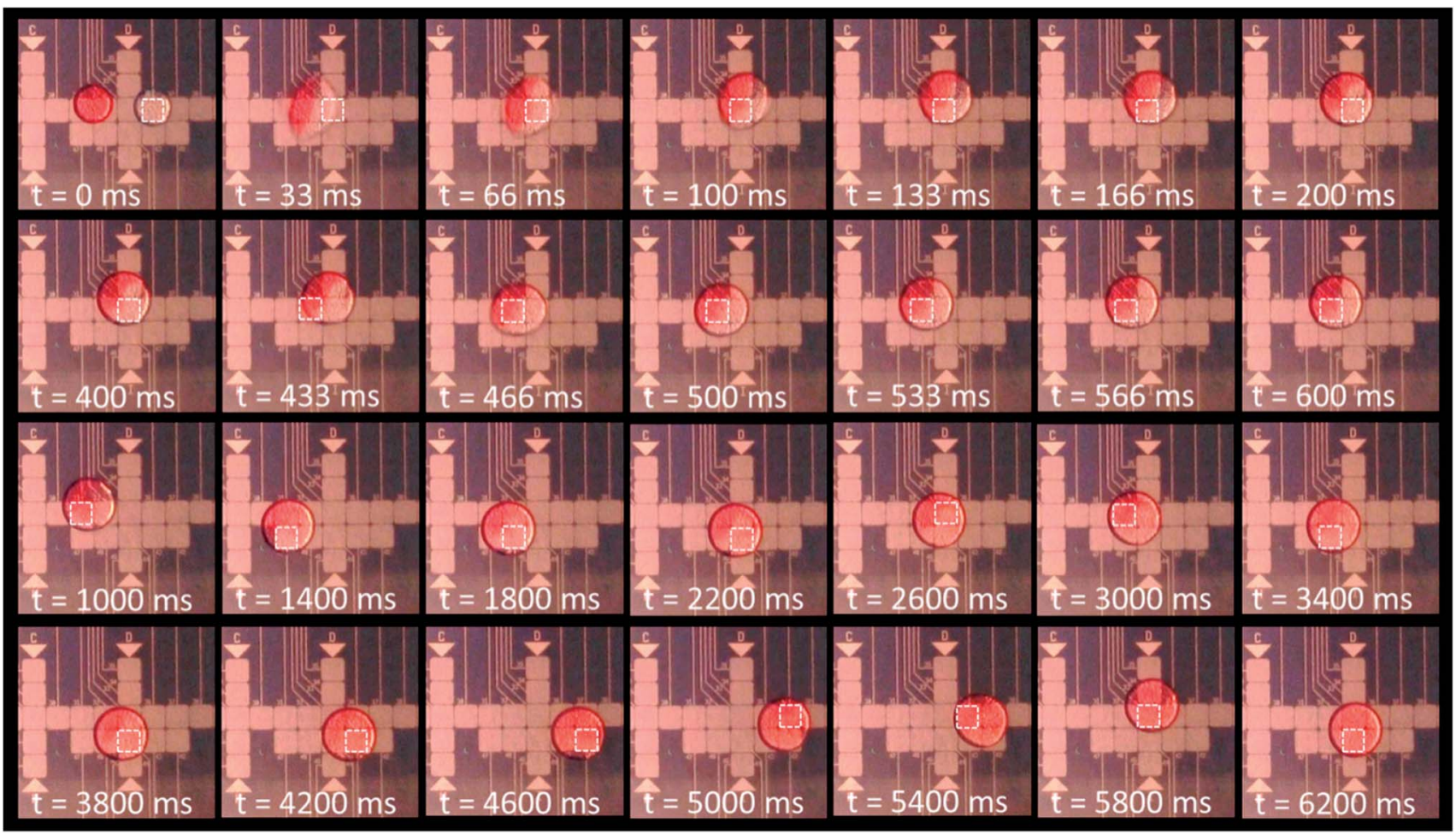

Fig. 9 Timed video frames of two $5 \mu$ droplets merging and mixing in a region of a parallel-plate superhydrophobic DMF device. Both droplets are DI water solutions; the left one is pre-mixed with New Coccine dye. The white-dash contoured pads represent the energised pad. The first row shows the 30-fps frame-by-frame record of the two droplets merging together. The second row displays the frame-by-frame record of the merged droplets' actuation from one pad to one another until the complete stabilisation of the droplet. Finally, the third and fourth row (from $t=$ $1000 \mathrm{~ms}$ to $t=6200 \mathrm{~ms}$ ) show the step-by-step mixing of the droplet; every frame is recorded after complete stabilisation of the droplet on the energised pad. 
dyed droplet causing them to coalesce into one $10 \mu \mathrm{l}$ unmixed droplet containing two clearly separated region, one of pure DI water and the other of dyed solution. After merging, the droplet is actuated following a mixing route that induces advection. Visibly complete mixing is achieved after only 12 actuation steps $(t=5 \mathrm{~s}$ with a $5 \mathrm{~Hz}$ switching rate). Each one of those steps involves a rapid actuation of the merged droplet (instantaneous velocity up to $3.1 \mathrm{~cm} \mathrm{~s}^{-1}$ as measured previously) toward the energised electrode. Due to inertia and thanks to very low friction on the superhydrophobic coating, the droplet is propelled slightly further than the energised electrode edge before moving back at the electrostatic equilibrium position. It is believed that this behaviour participates in the rapid and efficient mixing. A video clip of the two droplets merging and mixing is available in the ESI (Video $4 \dagger$ ).

Merging and mixing using the superhydrophobic DMF device can be achieved quite efficiently. However, attempts to split the droplet using traditional DMF splitting techniques ${ }^{58-60}$ have been unsuccessful. Necking of the droplet, which is a conditio sine qua non to traditional droplet splitting, wasn't observed even using a reservoir pad with a surface more than eight times bigger than the delivery pads. The high contact angle $\left(>160^{\circ}\right)$, in air, against the cover plate, resembles the configuration of a single-plate system, on which splitting is notoriously challenging if even possible at all, ${ }^{61-63}$ rendering the problem non-trivial. Further studies would be required to evaluate the possibility of droplet splitting. Alternative approaches for splitting droplet on EWOD chips exists such as the use of Y-junction ${ }^{64}$ or the use of micro-blade splitters; ${ }^{65}$ which might be envisaged to achieve droplet splitting on derivatives of the present device but are out of scope of the present paper.

In summary, droplets of both DI and very concentrated protein solutions have been successfully actuated using the two most common EWOD configurations, namely the 'open' and 'closed' configurations. Interestingly, the results of our demonstration have shown that the typical square control electrodes design $\mathbf{1}^{\mathbf{1 - 4 6 - 8 , 1 3 , 1 7 - 2 2}}$ is also feasible for droplet transportation with an ungrounded cover plate by coating both base and cover plates with superhydrophobic material. It is proposed that this configuration is viable with superhydrophobic surfaces because of the almost frictionless contact with the cover plate. In addition, although droplet splitting hasn't been achieved, merging and efficient mixing have both been performed on our device.

\section{Conclusions}

In order to address the general issue of biofouling in DMF devices intended for bioassay applications, commercial superhydrophobic material is proposed as the coating for the actuation surfaces in EWOD-based DMF devices. NeverWet ${ }^{\circledR}$ top coating (TNW) was used as a superhydrophobic coating for both the base and cover plates of a fully superhydrophobic device. Electrowetting of protein-concentrated droplets have displayed good electrowetting reversibility on TNW indicating its suitability as a EWOD actuating surface. When compared to Cytop ${ }^{\circledR}$ it also displayed a lower rolling off angle at high protein concentration after voltage application and a significant reduction of the biofouling rate on TNW as evidenced by measurements of the mean fluorescence intensity of adsorbed labelled proteins. Reliable actuation of very high protein concentrations up to $1 \mathrm{mg} \mathrm{ml}^{-1}$ of ovalbumin and $0.1 \mathrm{mg} \mathrm{ml}^{-1}$ of fibrinogen has been achieved on both 'open' and 'closed' common EWOD configurations of the superhydrophobic devices, demonstrating the high potential of the method for anti-biofouling strategies.

Quite surprisingly, there are very few reports of fully superhydrophobic EWOD actuation. To the best of the authors' knowledge, this is the first time that reliable actuation of highly concentrated protein droplets has been demonstrated on such a device. Further development is still needed to address challenges of the current technology such as superhydrophobic surface robustness as TNW is easily scratched and (whilst not objectively quantified) degrades with time. Another issue concerns splitting of the droplet that could not be achieved using the traditional method and would require further study of alternative technique in the future. A third challenge concerns droplet dispensing into a superhydrophobic microenvironment: droplets resist initial placement on to the device due to its very low surface energy and can also roll-off directly from dispensing very easily if care is not taken. To ease the dispensing process, the first electrode, immediately adjacent to the dispensing point, is energised so that the surface is hydrophilic to the droplet and the outer surface of the micropipette tip is also coated with TNW to avoid the droplet from sticking to the tip due to its relative hydrophilicity.

Nonetheless, fully superhydrophobic DMF devices, thanks to their biofouling-reduction characteristics, have the promising potential to address one of the major current general challenges of the EWOD technology, namely actuation of 'real-life' samples containing biomolecules.

\section{Conflicts of interest}

There are no conflicts to declare.

\section{Acknowledgements}

The authors gratefully acknowledge Dato' Azmil Khalid for the generous contribution of funding of Eli N. Abdul Latip's PhD scholarship, which has made this study possible. The authors also wish to thank their colleagues, Richard Kaye and Matthew Lodge, for their kind help with the 3D renders included in this paper.

\section{References}

1 K. Choi, A. H. C. Ng, R. Fobel, D. A. Chang-Yen, L. E. Yarnell, E. L. Pearson, C. M. Oleksak, A. T. Fischer, R. P. Luoma, J. M. Robinson, J. Audet and A. R. Wheeler, Anal. Chem., 2013, 85, 9638-9646.

2 R. S. Sista, A. E. Eckhardt, V. Srinivasan, M. G. Pollack, S. Palanki and V. K. Pamula, Lab Chip, 2008, 8, 2188-2196. 
3 R. Fobel, A. E. Kirby, A. H. Ng, R. R. Farnood and A. R. Wheeler, Adv. Mater., 2014, 26, 2838-2843.

4 A. H. Ng, K. Choi, R. P. Luoma, J. M. Robinson and A. R. Wheeler, Anal. Chem., 2012, 84, 8805-8812.

5 S. Sun, M. Yang, Y. Kostov and A. Rasooly, Lab Chip, 2010, 10, 2093-2100.

6 R. Sista, Z. S. Hua, P. Thwar, A. Sudarsan, V. Srinivasan, A. Eckhardt, M. Pollack and V. Pamula, Lab Chip, 2008, 8, 2091-2104.

7 Y. H. Chang, G. B. Lee, F. C. Huang, Y. Y. Chen and J. L. Lin, Biomed. Microdevices, 2006, 8, 215-225.

8 Z. S. Hua, J. L. Rouse, A. E. Eckhardt, V. Srinivasan, V. K. Pamula, W. A. Schell, J. L. Benton, T. G. Mitchell and M. G. Pollack, Anal. Chem., 2010, 82, 2310-2316.

9 S. H. Lee, S.-W. Kim, J. Y. Kang and C. H. Ahn, Lab Chip, 2008, 8, 2121-2127.

10 C. D. Chin, V. Linder and S. K. Sia, Lab Chip, 2012, 12, 21182134.

11 E. K. Sackmann, A. L. Fulton and D. J. Beebe, Nature, 2014, 507, 181-189.

12 R. B. Fair, Microfluid. Nanofluid., 2007, 3, 245-281.

13 M. G. Pollack, R. B. Fair and A. D. Shenderov, Appl. Phys. Lett., 2000, 77, 1725-1726.

$14 \mathrm{~J}$. Berthier and K. A. Brakke, The physics of microdroplets, John Wiley \& Sons, Hoboken, New Jersey, 2012.

15 F. Mugele and J.-C. Baret, J. Phys.: Condens. Matter, 2005, 17, R705-R774.

16 J. Lee, H. Moon, J. Fowler, T. Schoellhammer and C.-J. Kim, Sens. Actuators, A, 2002, 95, 259-268.

17 S. K. Cho, H. Moon and C.-J. Kim, J. Microelectromech. Syst., 2003, 12, 70-80.

18 H. Moon, S. K. Cho, R. L. Garrell and C.-J. C. Kim, J. Appl. Phys., 2002, 92, 4080-4087.

19 S. C. Shih, I. Barbulovic-Nad, X. Yang, R. Fobel and A. R. Wheeler, Biosens. Bioelectron., 2013, 42, 314-320.

20 S. C. Shih, R. Fobel, P. Kumar and A. R. Wheeler, Lab Chip, 2011, 11, 535-540.

21 M. G. Pollack, A. D. Shenderov and R. B. Fair, Lab Chip, 2002, 2, 96-101.

22 R. Fobel, C. Fobel and A. R. Wheeler, Appl. Phys. Lett., 2013, 102, 193513.

23 F. Saeki, J. Baum, H. Moon, J.-Y. Yoon, C. Kim and R. Garrell, Polym. Mater. Sci. Eng., 2001, 85, 12-13.

24 Y.-J. Liu, D.-J. Yao, H.-C. Lin, W.-Y. Chang and H.-Y. Chang, J. Micromech. Microeng., 2008, 18, 045017.

25 U.-C. Yi and C.-J. Kim, J. Micromech. Microeng., 2006, 16, 2053.

26 U.-C. Yi and C.-J. Kim, The 13th International Conference on Solid-State Sensors, Actuators and Microsystems, 2005, Digest of Technical Papers. TRANSDUCERS'05, 2005, vol. 1, pp. 8992.

27 J.-Y. Yoon and R. L. Garrell, Anal. Chem., 2003, 75, 50975102.

28 V. N. Luk, G. C. Mo and A. R. Wheeler, Langmuir, 2008, 24, 6382-6389.

29 G. Perry, V. Thomy, M. R. Das, Y. Coffinier and R. Boukherroub, Lab Chip, 2012, 12, 1601-1604.
30 M. Jönsson-Niedziółka, F. Lapierre, Y. Coffinier, S. Parry, F. Zoueshtiagh, T. Foat, V. Thomy and R. Boukherroub, Lab Chip, 2011, 11, 490-496.

31 Y. Li, W. Parkes, L. I. Haworth, A. W. Ross, J. T. M. Stevenson and A. J. Walton, J. Microelectromech. Syst., 2008, 17, 14811488.

32 S. H. Au, P. Kumar and A. R. Wheeler, Langmuir, 2011, 27, 8586-8594.

33 M. Yafia, S. Shukla and H. Najjaran, J. Micromech. Microeng., 2015, 25, 057001.

34 A. Abadian and S. Jafarabadi-Ashtiani, Microfluid. Nanofluid., 2014, 16, 989-995.

35 L. Mats, R. Young, G. T. Gibson and R. D. Oleschuk, Sens. Actuators, B, 2015, 220, 5-12.

36 N. Verplanck, Y. Coffinier, V. Thomy and R. Boukherroub, Nanoscale Res. Lett., 2007, 2, 577-596.

37 S. Wang and L. Jiang, Adv. Mater., 2007, 19, 3423-3424.

38 K.-S. Yun and C.-J. Kim, IEEE 20th International Conference on Micro Electro Mechanical Systems (MEMS), 2007, pp. 139-142.

39 F. Lapierre, V. Thomy, Y. Coffinier, R. Blossey and R. Boukherroub, Langmuir, 2009, 25, 6551-6558.

40 J. L. Campbell, M. Breedon, K. Latham and K. KalantarZadeh, Langmuir, 2008, 24, 5091-5098.

41 J. Zhou, S. Yang, X. Zeng, J. Wu, G. Chen and Y. Huang, J. Adhes. Sci. Technol., 2012, 26, 2087-2098.

42 N. Verplanck, E. Galopin, J.-C. Camart, V. Thomy, Y. Coffinier and R. Boukherroub, Nano Lett., 2007, 7, 813817.

43 D. L. Herbertson, C. R. Evans, N. J. Shirtcliffe, G. McHale and M. I. Newton, Sens. Actuators, A, 2006, 130, 189-193.

44 M. S. Dhindsa, N. R. Smith, J. Heikenfeld, P. D. Rack, J. D. Fowlkes, M. J. Doktycz, A. V. Melechko and M. L. Simpson, Langmuir, 2006, 22, 9030-9034.

45 S. L. Freire and B. Tanner, Langmuir, 2013, 29, 9024-9030.

46 I. Rust-Oleum Corporation: Vernon Hills, NeverWet Base Coat and Top Coat: MSDS No. 274234, http:// www.rustoleum.com/MSDS/ENGLISH/274234.pdf, accessed November 26, 2015.

47 E. Ostuni, R. G. Chapman, R. E. Holmlin, S. Takayama and G. M. Whitesides, Langmuir, 2001, 17, 5605-5620.

48 W. Yang, S. Chen, G. Cheng, H. Vaisocherova, H. Xue, W. Li, J. Zhang and S. Jiang, Langmuir, 2008, 24, 9211-9214.

49 A. Venault, K.-J. Hsu, L.-C. Yeh, A. Chinnathambi, H.-T. Ho and Y. Chang, Colloids Surf., B, 2017, 151, 372-383.

50 C. Extrand and S. I. Moon, Langmuir, 2010, 26, 17090-17099. 51 V. K. Sikka, M. Hurley and Z. W. Lim, U.S. Pat. 9,139,744, 2015.

52 A. Torkkeli, Droplet microfluidics on a planar surface, VTT Technical Research Centre of Finland, 2003.

53 L.-C. Xu and C. A. Siedlecki, Biomaterials, 2007, 28, 32733283.

54 A. Quinn, R. Sedev and J. Ralston, J. Phys. Chem. B, 2005, 109, 6268-6275.

55 S. Chevalliot, S. Kuiper and J. Heikenfeld, J. Adhes. Sci. Technol., 2012, 26, 1909-1930.

56 H. Verheijen and M. Prins, Langmuir, 1999, 15, 6616-6620. 
57 J. K. Park, S. J. Lee and K. H. Kang, Biomicrofluidics, 2010, 4, 024102.

58 S. K. Cho, H. Moon and C.-J. Kim, J. Microelectromech. Syst., 2003, 12, 70-80.

59 J. Song, R. Evans, Y.-Y. Lin, B.-N. Hsu and R. Fair, Microfluid. Nanofluid., 2009, 7, 75-89.

60 M. Yafia and H. Najjaran, Sens. Actuators, B, 2013, 186, 343352.

61 C. G. Cooney, C.-Y. Chen, M. R. Emerling, A. Nadim and J. D. Sterling, Microfluid. Nanofluid., 2006, 2, 435-446.
62 K. Choi, A. H. Ng, R. Fobel and A. R. Wheeler, Annu. Rev. Anal. Chem., 2012, 5, 413-440.

63 S. C. Shih, P. C. Gach, J. Sustarich, B. A. Simmons, P. D. Adams, S. Singh and A. K. Singh, Lab Chip, 2015, 15, 225-236.

64 N. J. B. Nikapitiya, S. M. You and H. Moon, IEEE 27th International Conference on Micro Electro Mechanical Systems (MEMS), 2014, pp. 955-958.

65 C. Dong, Y. Jia, J. Gao, T. Chen, P.-I. Mak, M.-I. Vai and R. P. Martins, Lab Chip, 2017, 17, 896-904. 